\title{
Virtual Clutch Controller for Clutch-to-Clutch Shifts in Planetary-Type Automatic Transmission
}

\author{
Yunjiang Cheng, ${ }^{1}$ Peng Dong, ${ }^{2}$ Shuai Yang, ${ }^{1}$ and Xiangyang Xu ${ }^{1}$ \\ ${ }^{1}$ School of Transportation Science and Engineering, Beihang University, Beijing 100191, China \\ ${ }^{2}$ Chair of Industrial and Automotive Drivetrains, Department of Mechanical Engineering, Ruhr-University Bochum, \\ 44801 Bochum, Germany \\ Correspondence should be addressed to Peng Dong; peng.dong@rub.de
}

Received 14 November 2014; Accepted 20 January 2015

Academic Editor: Honglei Xu

Copyright (C) 2015 Yunjiang Cheng et al. This is an open access article distributed under the Creative Commons Attribution License, which permits unrestricted use, distribution, and reproduction in any medium, provided the original work is properly cited.

\begin{abstract}
It is known that the shift processes of the four types of clutch-to-clutch shifts can theoretically be divided into two phases which are torque phase and inertia phase, but the execution orders are different. Two virtual clutch controllers are designed with the same eight states which include all control processes for these shifts. An equivalent method is proposed so that AT can be controlled just like DCT by adopting the torque ratios of oncoming clutch and offgoing clutch of each gear. The powertrain system model and the shift controller are established on Matlab/Simulink platform. The clutch-to-clutch shift processes have been studied based on the virtual clutch controller by software-in-the-loop simulations. Some typical problems in the clutch-to-clutch shift control are discussed and several control methods are compared to solve these problems.
\end{abstract}

\section{Introduction}

The planetary-type automatic transmission (AT) and the dual clutch transmission (DCT) are two widely equipped stepped automatic transmissions in the automotive industry. They both can accomplish gear shift without power interruption to improve driving comfort. In the early days of AT, the one-way clutches which can automatically disengage if the input torque becomes negative are used to improve the clutch-to-clutch shift quality. However, the use of one-way clutches requires additional shift elements and complicates the structure. Since 21st century, the development of DCT has become a hotspot study in the automotive industry due to the development of faster and more capable transmission control unit (TCU) which makes the precise control of clutchto-clutch shifts possible. However, due to the high cost of the dual mass fly wheel (DMFW), which is used to isolate engine vibration from the transmission and drive train, and the dual clutch module, the DCT has no obvious advantage of cost compared to AT. In addition, there is one more preselection actuator for the synchronizers of DCT that also complicates the control of gearshift process. On the contrary, the highperformance TCU can also be used in AT to abolish oneway clutches to lower the cost, and the mechanical efficiency of AT can be improved extensively by locking up the torque converter clutch after the launch of vehicle. And these need to be based on the precise clutch-to-clutch shift control technologies.

The control technologies for clutch-to-clutch shifts have been studied by many researches in both AT and DCT. For the researches on AT, the sliding model control is used by Runde [1] and the optimization of gearshift based on a model is studied by Haj-Fraj and Pfeiffer [2], but these methods are difficult to apply in practice; a robust adaptive control scheme with intelligent supervisor is studied by Kim et al. [3]; the hydraulic washout technique based on open loop control is developed by Bai and Moses [4]; the clutch engagement judder and stick-slip during the shift process are studied by Crowther et al. [5]. For the researches on DCT, the engine torque reduction control and transmission output torque control during the inertia phase are used by Goetz $[6,7]$; the modeling, simulation, and experimental analysis 


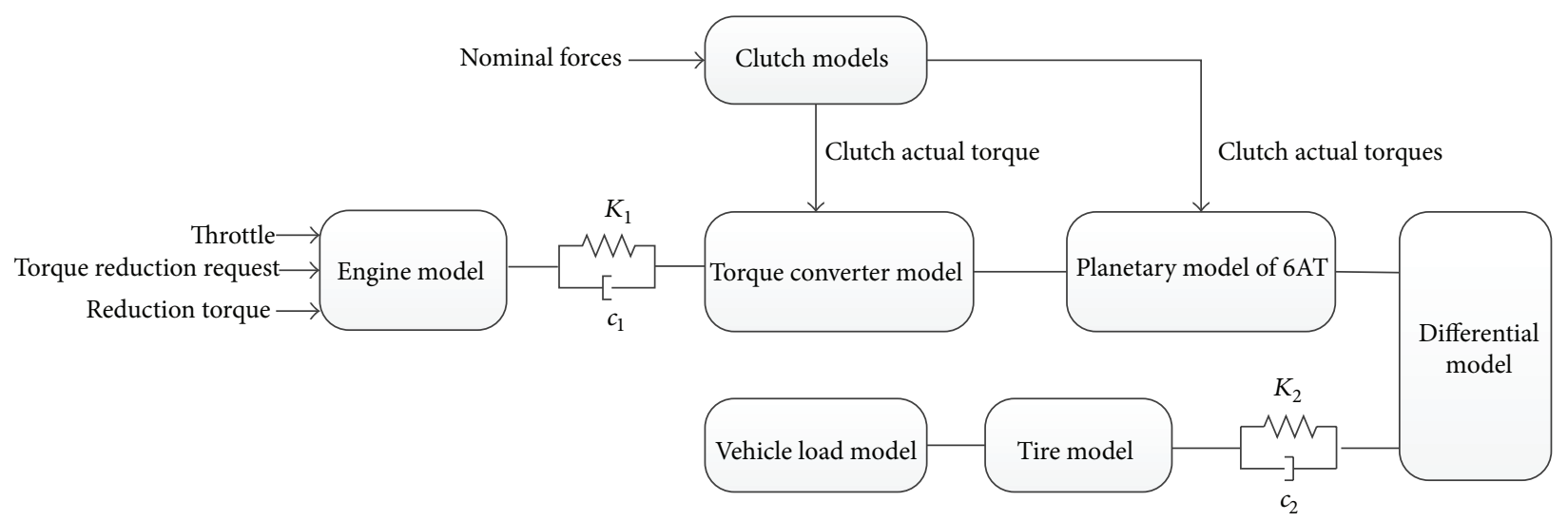

FIgURE 1: Outline of the powertrain dynamic model.

of clutch-to-clutch shifts have been conducted by Liu [8,9]; the extensive vibration analysis of shift process has been studied by Walker [10, 11]; the constant output torque control technology based on a power-based integrated powertrain control system has been developed by Bai et al. [12].

There are four types of clutch-to-clutch shifts, that is, power-on upshift, power-on downshift, power-off upshift, and power-off downshift. When the power is transferred from the input side to the output side of the transmission, the shift is called power-on shift; otherwise, the shift is called poweroff shift. The shift processes of the four types can theoretically be divided into two phases which are torque phase and inertia phase, but the execution orders are different. The poweron upshift and power-off downshift go through the torque phase before the inertia phase; on the contrary, the poweron downshift and power-off upshift get through the inertia phase before the torque phase.

The clutch-to-clutch shift is also known as a singletransition shift which means only one offgoing clutch needs to be released and one oncoming clutch needs to be engaged. Therefore, the two clutches need to be controlled during the shift. In this paper, the control algorithms of the offgoing clutch and the oncoming clutch are designed with eight states which include all control processes for the four types of clutch-to-clutch shifts. It is known that the principle of clutchto-clutch shifts in AT is the same to that in DCT. However, the number of clutches in an AT is more than that in a DCT which has only two clutches in most cases, and the clutches are often not at the input side of AT. An equivalent method is proposed to solve the problem. Two "virtual" clutches, that is, virtual oncoming clutch and virtual offgoing clutch, are assumed to exist at the input side of AT by adopting the torque ratios of oncoming clutch and offgoing clutch of each gear.

This paper starts with a brief overview of the dynamic model of the powertrain system. In the next section, the torque ratios of the clutches in 6AT have been derived for the virtual clutch controller. This is then followed by an introduction of the upper controller which manages the shift process of clutch-to-clutch shifts. Then the virtual clutch controller with eight states is proposed in detail. At the end of this paper, the clutch-to-clutch shift processes have been studied based on the virtual clutch controller. Some typical problems in the clutch-to-clutch shift control are discussed, such as clutch tie-up or input speed flare at the end of the torque phase, the torque "hump" during the inertia phase, and the output torque vibration at the end of the inertia phase. And several control methods are compared to solve these problems.

\section{The Dynamic Model of the Powertrain System}

A brief outline of the dynamic model of the powertrain system is given in this section. In order to study control algorithms for clutch-to-clutch shifts, the powertrain system model should be built appropriately. A low order model can reduce the computational demand, but on the other hand it must be complex enough that it represents the relevant dynamics of the powertrain system. Therefore, a 7degree-of-freedom (DOF) powertrain model is developed in the research which includes an engine model, seven clutch models, a torque converter model, a planetary model of 6AT, a differential model, a tire model, and a vehicle load model, as shown in Figure 1.

The engine map model is adopted. The experimental data of the mean engine torque is shown in Figure 2. During the clutch-to-clutch shift process, the engine torque may need to be controlled for the synchronization of oncoming clutch speed. Therefore, the model is designed to have the ability for torque reduction control, and the delay of torque response is modeled by a first-order damp element. The engine drag torque is also considered in the model.

The powertrain system contains a torque converter clutch and six multidisc clutches. The piecewise clutch model which contains two sets of equation of motion is adopted to divide the clutch state into slip state and slip state.

The steady-state torque converter model is adopted, and the torque ratio and $K$-factor data are provided by the component supplier, as shown in Figure 3.

The study object 6AT consisted of two simple minus planetary gear sets and one compound planetary gear set, 


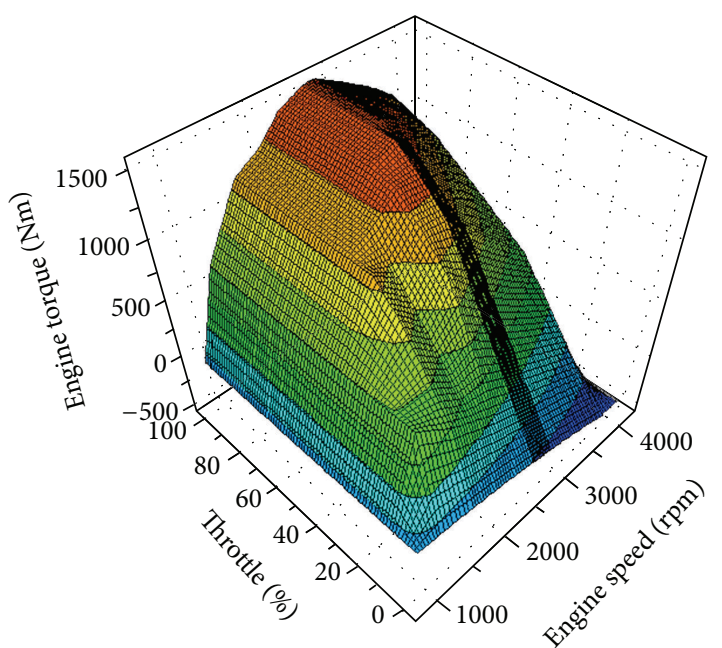

Figure 2: Engine map model.

as shown in Figure 4. The use of shift elements is shown in Table 1. The Lagrange method is an efficient way to describe the dynamic model of planetary gear sets and is adopted.

Equation (1) is the general form of Lagrange equations of the first kind for systems with linear speed constraints [13], and (2) is the form of the linear speed constraint equations:

$$
\begin{array}{r}
\frac{d}{d t}\left(\frac{\partial L}{\partial \dot{\theta}_{j}}\right)-\frac{\partial L}{\partial \theta_{j}}-Q_{j}+\sum_{i=1}^{S} \lambda_{i} \frac{\partial f_{i}}{\partial \theta_{j}}+\sum_{i=1}^{r} F_{i} A_{i j}=0, \\
(j=1,2, \ldots, m),
\end{array}
$$

$$
\begin{array}{r}
\sum_{j=1}^{m} A_{i j}\left(\theta_{1}, \theta_{2}, \ldots, \theta_{m}, t\right) \dot{\theta}_{j}+b_{i}\left(\theta_{1}, \theta_{2}, \ldots, \theta_{m}, t\right)=0, \\
(i=1,2, \ldots, r),
\end{array}
$$

where $\partial$ is a partial derivative; $L$ is the Lagrange function; $\theta$ is the generalized coordinate; $Q$ is the generalized nonpotential force; $F$ and $\lambda$ are the Lagrange multipliers, also known as the internal forces; $m$ is the number of generalized coordinates; $S$ is the number of constraint equations; and $r$ is the number of linear speed constraint equations.

Under the condition of ideal constraint, four independent speed constraint equations of the system can be obtained, as shown in (3):

$$
\begin{aligned}
& R_{s 1} \cdot \dot{\theta_{1}}+R_{r 1} \cdot \dot{\theta_{3}}=\left(R_{s 1}+R_{r 1}\right) \cdot \dot{\theta_{4}}, \\
& R_{s 2} \cdot \dot{\theta_{1}}+R_{r 2} \cdot \dot{\theta_{5}}=\left(R_{s 2}+R_{r 2}\right) \cdot \dot{\theta_{3}}, \\
& R_{s 3} \cdot \dot{\theta_{6}}+R_{r 3} \cdot \dot{\theta_{3}}=\left(R_{s 3}+R_{r 3}\right) \cdot \dot{\theta_{2}}, \\
& -R_{s 3} \cdot \dot{\theta_{6}}+R_{r 4} \cdot \dot{\theta_{7}}=\left(R_{r 4}-R_{s 3}\right) \cdot \dot{\theta_{2}},
\end{aligned}
$$

where $R_{s i}$ is the radius of circle passing through the center of the $i$ th sun gear; $R_{r i}$ is the radius of circle passing through the center of the $i$ th ring gear; $\theta_{i}$ is the rotational displacement of the $i$ th shaft, as shown in Figure 4.

According to (1)-(3), the dynamic equations of planetary system of 6AT can be obtained in matrix format, as shown in (4):

$$
\mathbf{M} \cdot \mathbf{\Omega}=\mathbf{T} .
$$

Here,

$$
\begin{aligned}
& \mathbf{M}=\left[\begin{array}{ccccccccccc}
I_{1} & 0 & 0 & 0 & 0 & 0 & 0 & R_{s 1} & R_{s 2} & 0 & 0 \\
0 & I_{2} & 0 & 0 & 0 & 0 & 0 & 0 & 0 & -R_{s 3}-R_{r 3} & R_{s 3}-R_{r 4} \\
0 & 0 & I_{3} & 0 & 0 & 0 & 0 & R_{r 1} & -R_{s 2}-R_{r 2} & R_{r 3} & 0 \\
0 & 0 & 0 & I_{4} & 0 & 0 & 0 & -R_{s 1}-R_{r 1} & 0 & 0 & 0 \\
0 & 0 & 0 & 0 & I_{5} & 0 & 0 & 0 & R_{r 2} & 0 & 0 \\
0 & 0 & 0 & 0 & 0 & I_{6} & 0 & 0 & 0 & R_{s 3} & -R_{s 3} \\
0 & 0 & 0 & 0 & 0 & 0 & I_{7} & 0 & 0 & 0 & R_{r 4} \\
R_{s 1} & 0 & R_{r 1} & -R_{s 1}-R_{r 1} & 0 & 0 & 0 & 0 & 0 & 0 & 0 \\
R_{s 2} & 0 & -R_{s 2}-R_{r 2} & 0 & R_{r 2} & 0 & 0 & 0 & 0 & 0 & 0 \\
0 & -R_{s 3}-R_{r 3} & R_{r 3} & 0 & 0 & R_{s 3} & 0 & 0 & 0 & 0 & 0 \\
0 & R_{s 3}-R_{r 4} & 0 & 0 & 0 & -R_{s 3} & R_{r 4} & 0 & 0 & 0 & 0
\end{array}\right], \\
& \boldsymbol{\Omega}=\left[\begin{array}{lllllllllll}
\ddot{\theta_{1}} & \ddot{\theta_{2}} & \ddot{\theta_{3}} & \ddot{\theta_{4}} & \ddot{\theta_{5}} & \ddot{\theta_{6}} & \ddot{\theta_{7}} & F_{1} & F_{2} & F_{3} & F_{4}
\end{array}\right]^{T},
\end{aligned}
$$

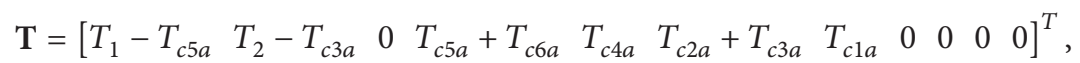


TABLE 1: Use of shift elements.

\begin{tabular}{lllllll}
\hline Gear & C1 & C2 & C3 & C4 & C5 & C6 \\
\hline D1 & $x$ & & & $x$ & & \\
D2 & & $x$ & & $x$ & & \\
D3 & & & $x$ & $x$ & & \\
D4 & $x$ & & & & $x$ & \\
D5 & & $x$ & & & $x$ & \\
D6 & & & $x$ & & $x$ & \\
R1 & $x$ & & & & & $x$ \\
R2 & & $x$ & & & & $x$ \\
R3 & & & $x$ & & & $x$ \\
\hline
\end{tabular}

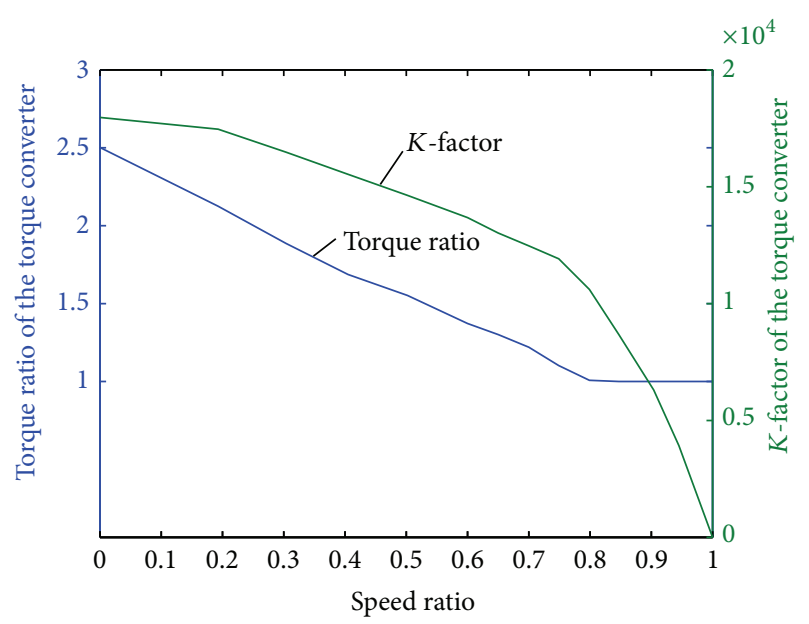

FIgURE 3: Performance characteristic curve of a torque converter.

where $I_{i}$ is the inertia of the $i$ th shaft; $F_{i}$ is the internal forces of planetary gear sets; and $T_{c i a}$ is the actual torque of the $i$ th clutch; $T_{1}$ is the input torque exerted on the turbine shaft; and $T_{2}$ is the load torque exerted on the output shaft of 6AT; see Figure 4.

The differential is modeled to be a simple connecting component to the final drive. The nonrigid characteristic of the drive shafts is considered by a spring-damper element. The tire is modeled according to the slip characteristic which is a curve using the approach published by Wohnhaas et al. [14]. The vehicle load model is established including gradient resistance, aerodynamic drag, and rolling resistance.

\section{Torque Ratios of the Clutches in 6AT}

It is known that the principle of clutch-to-clutch shifts in AT is the same to that in DCT. However, in most cases, the number of clutches in an AT is more than that in a DCT which has only two clutches, and the clutches are often not at the input side of AT. An equivalent method is proposed to solve the problem. Two "virtual" clutches, that is, virtual oncoming clutch and virtual offgoing clutch, are assumed to exist at the input side of AT by adopting the torque ratios of corresponding clutches of each gear.

There are six clutches for gearshift which are at different positions in 6AT; see Figure 4. Take the 4th drive gear of
6AT to explain this method, as shown in Figure 5. Clutch 1 (C1) and clutch 5 (C5) are engaged in this Figure. A "virtual clutch" (CV) is imagined at the input side of 6AT. In order to facilitate static analysis of the actual torque transferred by a clutch and slip speed of the clutches, assume the system is in an equilibrium state. Under the condition of ideal constraint (i.e., no backlash and no gear teeth compliance), the constraint equations of planetary gear sets are shown in (3). Because $\mathrm{Cl}$ and $\mathrm{C} 5$ are engaged, (6) can be obtained:

$$
\begin{gathered}
\dot{\theta_{1}}=\dot{\theta_{4}}, \\
\dot{\theta_{7}}=0 .
\end{gathered}
$$

Thus the actual torques of $\mathrm{CV}, \mathrm{Cl}$, and $\mathrm{C} 5$ can be obtained, as shown in the following:

$$
\begin{gathered}
T_{c v a}=T_{1}, \\
T_{c 1 a}=\left(\frac{R_{r 4}}{R_{r 3}}\right) \cdot T_{1}, \\
T_{c 5 a}=\left(1+\frac{R_{s 1}}{R_{r 1}}\right) \cdot T_{1} .
\end{gathered}
$$

Therefore, the torque ratios of $\mathrm{Cl}$ and $\mathrm{C} 5$ to $\mathrm{CV}$ can be obtained, as shown in the following:

$$
\begin{gathered}
\beta_{c 1 d 4}=\frac{R_{r 4}}{R_{r 3}} \\
\beta_{c 5 d 4}=1+\frac{R_{s 1}}{R_{r 1}} .
\end{gathered}
$$

Note that $\beta_{c i j}$ is the $i$ th clutch at the $j$ th gear; for example, $\beta_{c 5 d 4}$ denotes the torque ratio of $\mathrm{C} 5$ at the 4 th drive gear.

Through speed analysis, the slip ratios of $\mathrm{Cl}$ and $\mathrm{C} 5$ to $\mathrm{CV}$ are reciprocal relationships to the torque ratios, and the slip speed of $\mathrm{Cl}$ and $\mathrm{C} 5$ can be calculated by (9) and (10). The slip speed of $\mathrm{CV}$ can be calculated using the input speed, output speed, and current gear ratio, as shown in (11) as follows:

$$
\begin{gathered}
\Delta \dot{\theta_{c 5}}=\frac{\Delta \theta_{c v}}{\beta_{c 5 d 4}}, \\
\Delta \dot{\theta_{c 1}}=\frac{\Delta \dot{\theta}_{c v}}{\beta_{c 1 d 4}}, \\
\Delta \dot{\theta_{c v}}=\dot{\theta_{1}}-\dot{\theta_{2}} \cdot i_{d 4},
\end{gathered}
$$

where $\Delta \dot{\theta}_{c i}$ is the slip speed of the $i$ th clutch and $i_{d 4}$ is the speed ratio of the 4 th drive gear.

In the same way, the torque ratios of six drive gears and three reverse gears can be obtained, as shown in Table 2. By utilizing the torque ratios of the clutches, the 6AT can be controlled like a DCT for only two virtual clutches at the input side of the transmission; that is, an oncoming clutch and an offgoing clutch need to be controlled during each clutch-to-clutch shift process. The differences are that the target slip speed of virtual clutch needs to be calculated by 
TABLE 2: Torque ratios of the six clutches at each gear.

\begin{tabular}{|c|c|c|c|c|c|c|c|c|c|}
\hline$\beta_{c i j}$ & D1 & D2 & D3 & D4 & D5 & D6 & R1 & R2 & R3 \\
\hline $\mathrm{Cl}$ & $\left.\frac{R_{r 2}}{R_{s 2}}\right) \frac{R_{r 4}}{R_{r 3}}$ & & & $\frac{R_{r 4}}{R_{r 3}}$ & & & $-\frac{R_{r 1} R_{r 4}}{R_{s 1} R_{r 3}}$ & & \\
\hline C2 & & $\left.\frac{R_{r 2}}{R_{s 2}}\right) \frac{R_{s 3}}{R_{r 3}}$ & & & $\frac{R_{s 3}}{R_{r 3}}$ & & & $-\frac{R_{r 1} R_{s 3}}{R_{s 1} R_{r 3}}$ & \\
\hline C3 & & & $-\frac{R_{r 2}}{R_{s 2}}$ & & & $-\frac{R_{s 3}}{R_{r 3}}$ & & & $\frac{R_{r 1} R_{s 3}}{R_{s 1} R_{r 3}}$ \\
\hline $\mathrm{C} 4$ & $\frac{R_{r 2}}{R_{s 2}}$ & $\frac{R_{r 2}}{R_{s 2}}$ & $\frac{R_{r 2}}{R_{s 2}}$ & & & & & & \\
\hline C5 & & & & $1+\frac{R_{s 1}}{R_{r 1}}$ & $1+\frac{R_{s 1}}{R_{r 1}}$ & $1+\frac{R_{s 1}}{R_{r 1}}$ & & & \\
\hline C6 & & & & & & & $-1-\frac{R_{r 1}}{R_{s 1}}$ & $-1-\frac{R_{r 1}}{R_{s 1}}$ & $-1-\frac{R_{r 1}}{R_{s 1}}$ \\
\hline
\end{tabular}

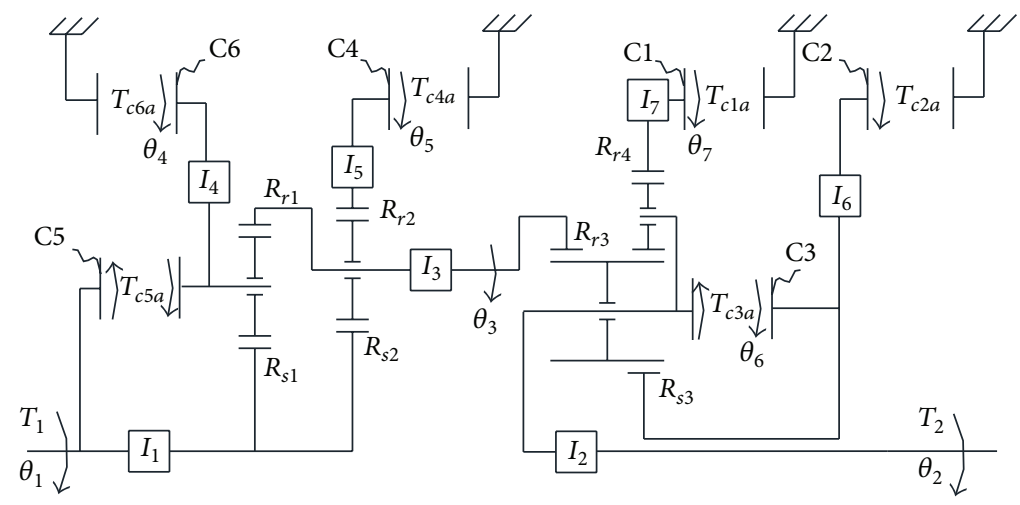

FiguRE 4: Structure of planetary system of 6AT.

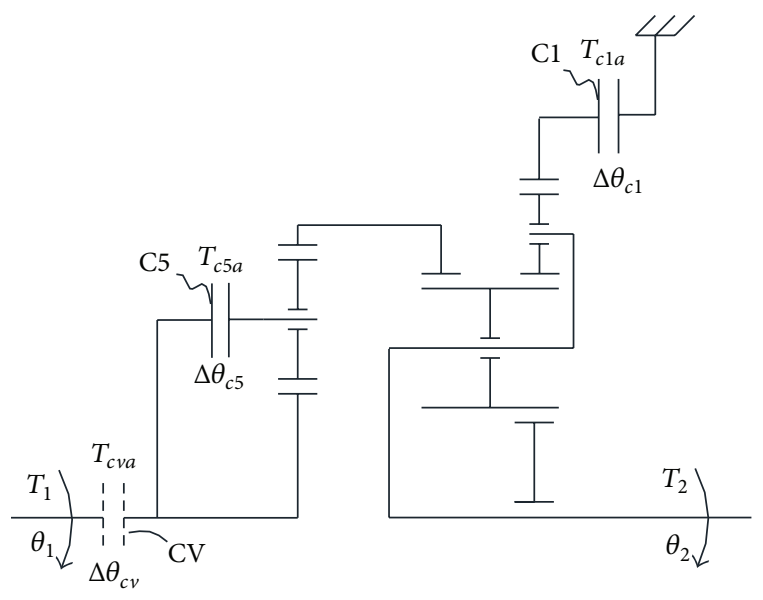

FIgURE 5: Structure of the 4th drive gear of 6AT.

multiplying the target slip speed of "real clutch" by the torque ratio of real clutch at the current gear before the controller, and the demand torque of real clutch needs to be calculated by multiplying the demand torque of virtual clutch by the torque ratio of real clutch at the current gear after the controller, as shown in Figure 11. By this method the six clutches of 6AT can be equivalent to two virtual clutches using the torque ratios of each gear, and thus the same control algorithm can be used to handle the shift processes of different gears. Therefore, the control algorithm can be simplified dramatically and thus the demand for the memory of TCU is decreased.

\section{Frame of the Shift Controller}

The shift controller of 6AT is designed with six parts, as shown in Figure 6. The execution sequence of them is shift schedule (SS), clutch role decision (CRD), generic control flow (GCF), virtual clutch information calculation (VCIC), oncoming virtual clutch controller (ONVCC), and offgoing virtual clutch controller (OFFVCC). In this section, the functionality of the SS, the CRD, and the GCF will be described.

The functionality of SS is to determine whether a clutchto-clutch shift process should be executed according to the throttle and vehicle speed.

The functionality of CRD is to determine the ID of oncoming clutch (IDON) and the ID of offgoing clutch (IDOFF) according to the use of shift elements; see Table 1.

The functionality of GCF is to manage overall process flow for clutch-to-clutch shifts, and command the lower controllers, that is, ONVCC and OFFVCC, to execute related control algorithms. The GCF is designed with four phases, that is, no shift phase (NSP), shift phase 1 (SP1), shift phase 2 (SP2), and shift phase 3 (SP3), as shown in Figure 7. 


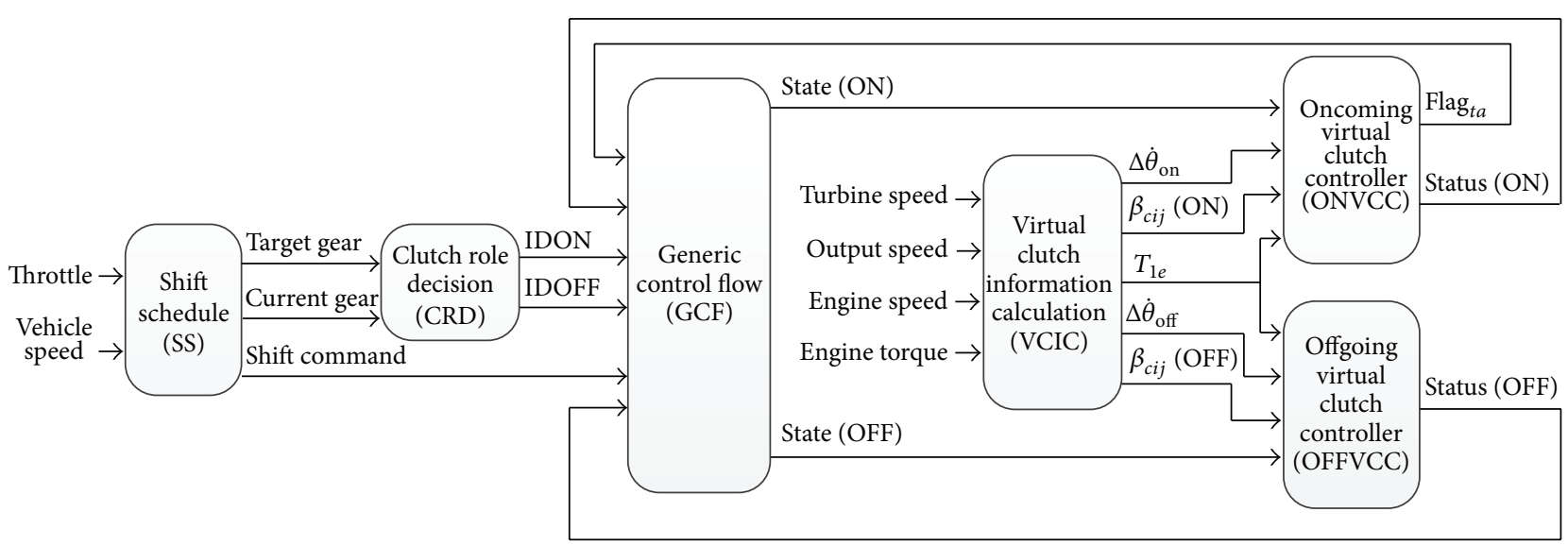

Figure 6: Frame of the shift controller of 6AT.

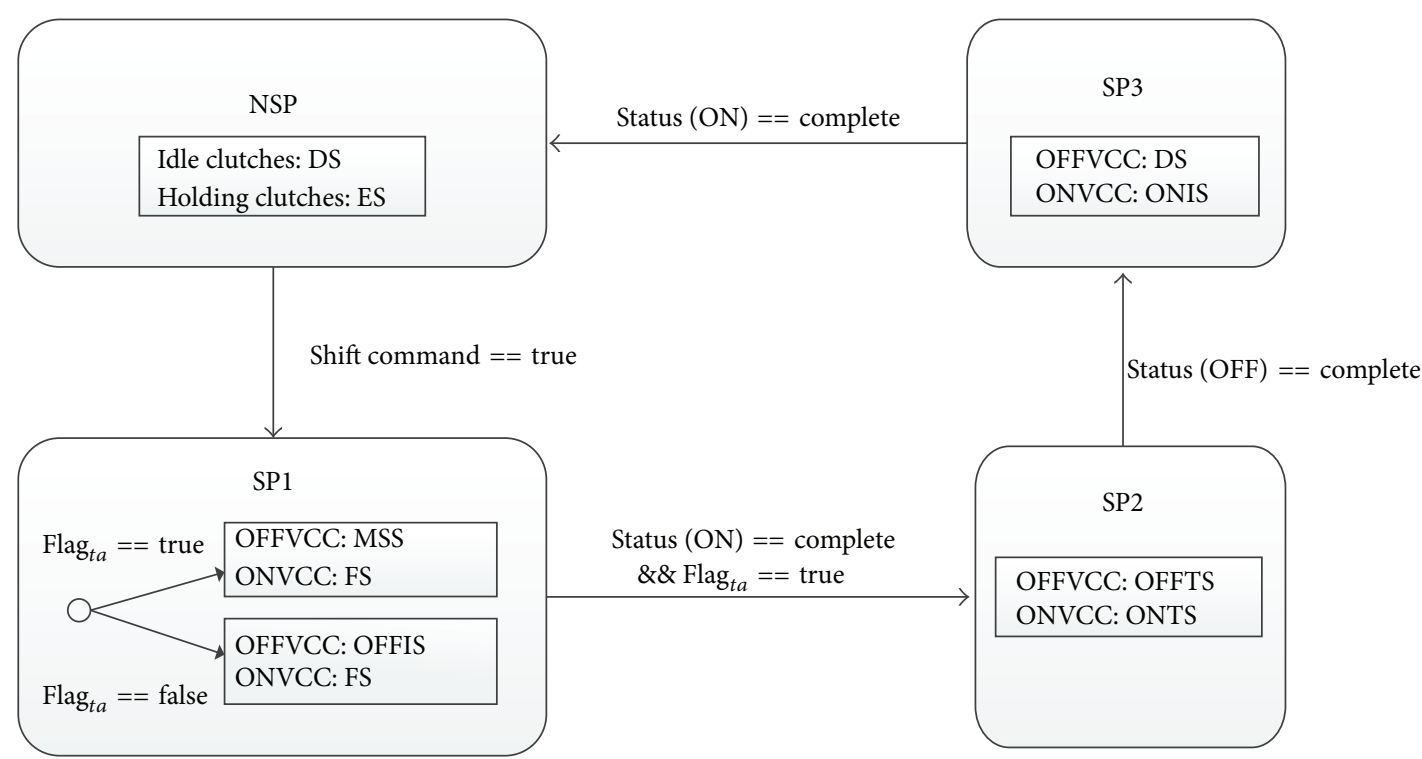

FIgURE 7: Schematic diagram of the generic control flow.

The functionality of VCIC is to calculate the data for the ONVCC and the OFFVCC. The slip speed of oncoming virtual clutch and offgoing virtual clutch is calculated by (12) and (13), respectively. The speed ratio of the torque converter is calculated by (14) and thus the torque ratio can be obtained according to Figure 3. The estimated input torque is calculated by (15) with the characteristics of the torque converter taken into consideration. The torque ratios of oncoming clutch and offgoing clutch can be obtained according to Table 2:

$$
\begin{gathered}
\Delta \dot{\theta}_{\mathrm{off}}=\dot{\theta_{1}}-\dot{\theta_{2}} \cdot i_{c}, \\
\Delta \dot{\theta_{\mathrm{on}}}=\dot{\theta}_{1}-\dot{\dot{\theta}_{2}} \cdot i_{t}, \\
i_{\mathrm{tc}}=\frac{\dot{\theta_{1}}}{\dot{\theta_{e}}} \\
T_{1 e}=\left(T_{e}-I_{e} \ddot{\theta_{e}}\right) \cdot \alpha\left(i_{\mathrm{tc}}\right)-I_{1} \ddot{\theta}_{1},
\end{gathered}
$$

where $\Delta \theta_{\text {on }}$ and $\Delta \theta_{\text {off }}$ are the slip speed of oncoming virtual clutch and offgoing virtual clutch; $i_{t}$ is the target gear ratio; $i_{c}$ is the current gear ratio; $i_{\mathrm{tc}}$ is the speed ratio of the torque converter; $\alpha\left(i_{\mathrm{tc}}\right)$ is the torque ratio of the torque converter; $T_{1 e}$ is the estimated input torque; $I_{e}$ is the engine inertia; $\theta_{e}$ is the rotational displacement of engine; and $T_{e}$ is the engine torque.

\section{Virtual Clutch Controller}

In order to simplify the algorithms of the shift controller, the ONVCC is designed exactly the same with the OFFVCC, and both of them are commanded by the upper controller, that is, the GCF. The ONVCC and the OFFVCC are designed with 8 states, that is, engage state (ES), disengage state (DS), fill state (FS), microslip state (MSS), oncoming torque state (ONTS), offgoing torque state (OFFTS), oncoming inertia state (ONIS), and offgoing inertia state (OFFIS), as shown in Figure 8. 
TABLE 3: Flow of states of the ONVCC and the OFFVCC.

\begin{tabular}{|c|c|c|c|c|c|c|}
\hline Shift types & GCF & NSP & SP1 & SP2 & SP3 & NSP \\
\hline \multirow{2}{*}{ Power-on upshift and power-off downshift } & ONVCC & DS & FS & ONTS & ONIS & ES \\
\hline & OFFVCC & ES & MSS & OFFTS & DS & DS \\
\hline \multirow{2}{*}{ Power-on downshift and power-off upshift } & ONVCC & DS & FS & ONTS & ONIS & ES \\
\hline & OFFVCC & ES & OFFIS & OFFTS & DS & DS \\
\hline
\end{tabular}

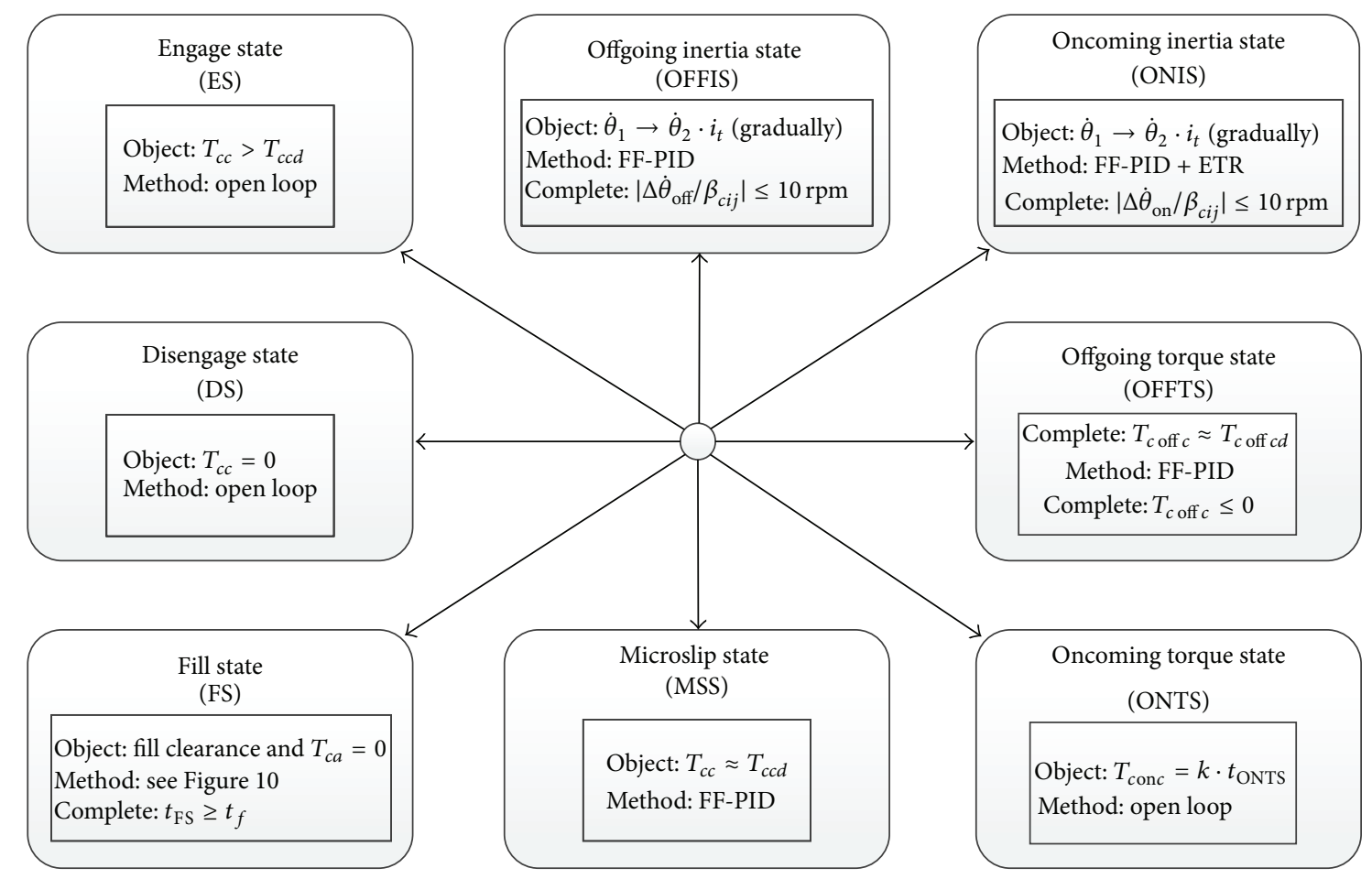

FIGURE 8: Virtual clutch controller.

According to the GCF, the flows of states of the ONVCC and the OFFVCC for the four types of clutch-to-clutch shifts can be summarized in Table 3 .

Before the description of the control methods of the eight states, three concepts about a clutch need to be explained. The first is the "torque capacity," which is the maximum torque the clutch can transfer and be controlled by the normal force applied on the clutch plates; the second is "actual torque," which is the torque transferred by a clutch [12]; the third is "drive torque capacity," which is the torque exerted on the drive shaft of a clutch and can be calculated by (16); see Figure 9:

$$
T_{c c d}=T_{c i n}-I_{c i n} \theta_{c i n}^{\ddot{\prime}},
$$

where $F_{n}$ is the nominal force; $T_{c \text { in }}$ is the torque exerted on the input side of the clutch; $I_{c i n}$ is the inertia of the input side; $\theta_{c \text { in }}^{\cdot}$ is the input side speed; $\theta_{\text {cout }}$ is the output side speed; and $\Delta \dot{\theta}_{c}$ is the slip speed, which equals $\theta_{\text {cin }}^{\cdot}-\theta_{\text {cout }}$.

In ES, the object is to keep the torque capacity of the clutch always larger than the drive torque capacity to ensure the clutch is in stick state. The open loop control method is

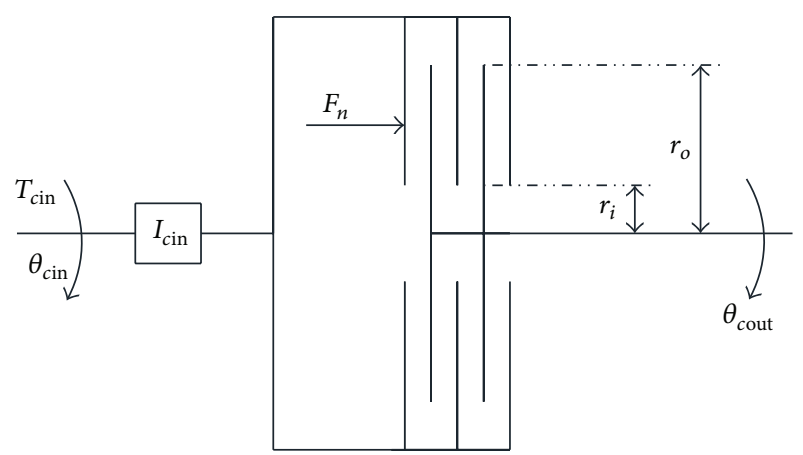

Figure 9: Sketch of a multidisc clutch.

adopted to accomplish the task. The demand pressure for the cylinder of the clutch is set to be the line pressure, so that sufficient control current is sent to the solenoid to ensure there is no slip of the clutch.

In DS, the object is to keep the torque capacity of the clutch equivalent to zero to ensure no actual torque is 
transferred by the clutch. The open loop control method is adopted. No control current is sent to the solenoid to ensure the torque capacity is zero.

In FS, the object is to make sure the clearance in the oil line of the clutch is filled up, but the actual torque of the clutch remains at zero. The open loop control method is chosen. The control current of the clutch changes following a given shape, as shown in Figure 10. Note that the fill time $\left(t_{f}\right)$, fast fill time $\left(t_{\text {fast }}\right)$, fast fill current $\left(i_{\text {fast }}\right)$, and kiss-point current $\left(i_{\text {kiss }}\right)$ are calibration parameters. When the duration time of FS $\left(t_{\mathrm{FS}}\right)$ exceeds the fill time, the status of the clutch (Status or Status off $)$ is set to complete status; otherwise, the status is set to progress status.

In MSS, the object is to keep the torque capacity of the clutch equivalent to the drive torque capacity. However, because there are noises in the engine torque signals and input speed signals, the drive torque capacity of the virtual clutch is calculated with error. In addition, the torque capacity is also imprecise due to the variable working conditions of the hydraulic system. Therefore, a combined controller including feed-forward control (FF) and PID control is designed to achieve the control object, as shown in Figure 11. The FF torques, that is, the drive torque capacities, of the oncoming virtual clutch and the offgoing virtual clutch are calculated by (17). In MSS, the target slip of the FF-PID controller is set to a small value, that is, $10 \mathrm{rpm}$ :

$$
\begin{aligned}
& T_{c \text { on } c d}=T_{1 e}-T_{c \text { off } a}, \\
& T_{c \text { off } c d}=T_{1 e}-T_{c \text { on } a},
\end{aligned}
$$

where $T_{c \text { on } c d}$ and $T_{c \text { off } c d}$ are the FF torques of the oncoming virtual clutch and the offgoing virtual clutch; $T_{c \text { on } a}$ and $T_{c \text { off } a}$ are the actual torques of the oncoming virtual clutch and the offgoing virtual clutch.

In ONTS, the object is to increase the actual torque of oncoming clutch to follow a slope in order to take over the torque from offgoing clutch smoothly. Therefore, the open loop control method is adopted. The torque capacity of oncoming virtual clutch rises linearly, as shown in the following:

$$
T_{\text {conc }}=T_{\text {con } a}=k \cdot t_{\mathrm{ONTS}},
$$

where $T_{c \text { on } c}$ is the torque capacity of oncoming virtual clutch and $t_{\text {ONTS }}$ is the duration time of ONTS.

In OFFTS, the object is to keep torque capacity equivalent to the drive torque capacity of offgoing clutch. The FF-PID controller is adopted in the same way with MSS. In order to avoid clutches "tie-up" phenomenon, small target slip, that is, $20 \mathrm{rpm}$, is set to the PID controller. When the torque capacity of offgoing virtual clutch reaches zero, the status of OFFVCC is set to complete status; otherwise, it is set to progress status.

In ONIS, the object is to control the turbine speed to reach the target gear speed level gradually in the inertia phase after torque phase. In order to accomplish the speed change, an inertia torque needs to be added on the oncoming clutch or be subtracted from the engine torque. The first method causes a torque "hump" in the inertia phase which reduces ride comfort. The engine torque reduction (ETR) can

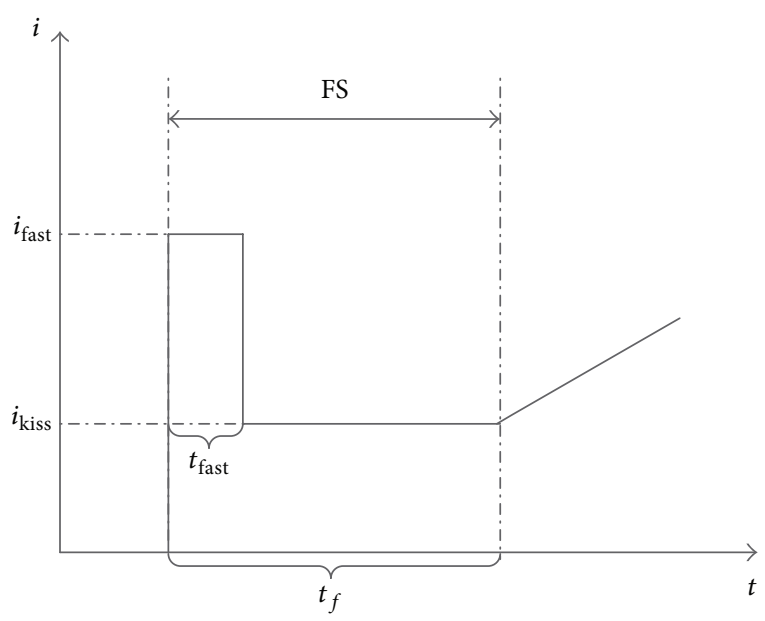

Figure 10: Control current in fill state.

avoid the torque "hump," but it cannot be used for power-off shifts and the accuracy of engine torque response is limited. Therefore, two methods are both used in this state. The engine reduction torque is calculated by (19), which considers the characteristics of the torque converter; see Figure 3. The FF-PID controller is also adopted. The target slip speed of oncoming virtual clutch decreases following the desired rate of the input speed. When the actual slip speed of oncoming virtual clutch is lower than a small slip (10 rpm), the status of ONVCC is set to complete status; otherwise, it is set to progress status:

$$
T_{\mathrm{rt}}=\frac{\theta_{\mathrm{ONIS}} I_{1}}{\alpha\left(i_{\mathrm{tc}}\right)}+\left(\frac{\theta_{\mathrm{ONIS}}^{\cdot \cdot}}{i_{\mathrm{tc}}}\right) \cdot I_{e},
$$

where $\theta_{\text {ONIS }}$ is the desired rate of the input speed in ONIS and $T_{\mathrm{rt}}$ is the engine reduction torque.

In OFFIS, the object is to control the turbine speed to the target gear speed level gradually in the inertia phase before torque phase. It is different from ONIS in the way that an inertia torque (calculated by (20)) needs to be subtracted from the actual torque of offgoing virtual clutch. The FFPID controller is also adopted, but the inertia torque is subtracted from the FF torque, as shown in (19). The target slip of offgoing clutch increases following the desired rate of the input speed. When the actual slip of oncoming clutch exceeds the small slip ( $10 \mathrm{rpm})$, the status of OFFVCC is set to complete status; otherwise, it is set to progress status:

$$
\begin{gathered}
T_{\mathrm{OFFIS}}=\theta_{\mathrm{OFFIS}} I_{1}+\left(\frac{\theta_{\mathrm{OFFIS}}}{i_{\mathrm{tc}}}\right) \cdot I_{e} \cdot \alpha\left(i_{\mathrm{tc}}\right) \\
T_{c \text { off } c d}=T_{1 e}-T_{c \text { on } a}-T_{\mathrm{OFFIS}}
\end{gathered}
$$

where $\theta_{\text {OFFIS }}{ }^{*}$ is the desired rate of the input speed in OFFIS and $T_{\text {OFFIS }}$ is the inertia torque in OFFIS. 


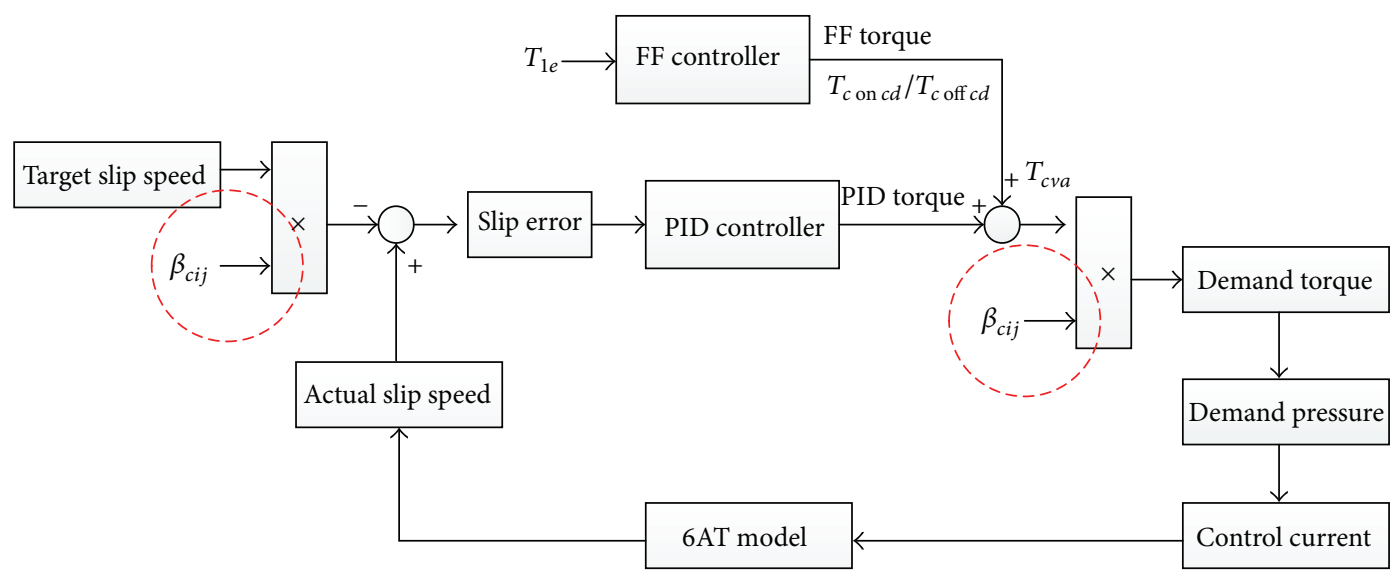

FIgUre 11: Principle of the FF-PID controller.

\section{Shift Control Results and Analysis}

6.1. Results of the Four Types of Shifts. Based on the shift controller with the ONVCC and the OFFVCC, the four types of clutch-to-clutch shifts are simulated, as shown in Figure 12. Figures 12(a), 12(b), 12(c), and 12(d) show the control current sent to the solenoids of offgoing clutch and oncoming clutch of power-on upshift, power-on downshift, power-off upshift, and power-off downshift, respectively. The four phases of the GCF and the state flows of the OFFVCC and the ONVCC are also indicated in these figures and are consistent with the designed flows; see Table 3. Figures 12(e), 12(f), 12(g), and $12(\mathrm{~h})$ picture the actual torques of offgoing clutch and oncoming clutch of the four types of shifts, respectively.

Before the clutch-to-clutch shift processes, the GCF is in NSP; therefore, the holding clutches are in ES and the idle clutches are in DS. When the SS determines a shift command, the GCF enters SP1, and then the shift process begins. For the power-on upshift and the power-off downshift, the OFFVCC is in MSS and the ONVCC is in FS; for the poweron downshift and the power-off upshift, the OFFVCC is in OFFIS and the ONVCC is in FS. When the oncoming clutch and the offgoing clutch are ready for the torque phase, the GCF enters SP2; therefore, the clutch-to-clutch torque handover process takes place. For the four types of shifts, the OFFVCC is in OFFTS and the ONVCC is in ONTS. When the torque phase is over, the GCF enters SP3. For the four types of shifts, the OFFVCC is in DS and the ONVCC is in ONIS. When the slip speed of oncoming clutch approaches zero, the speed synchronization of the oncoming clutch is complete and ONVCC turns to complete status. Then the GCF gets back to NSP. The clutch-to-clutch shift process is complete in the meantime.

Based on the virtual clutch controller, the processes of torque phase and inertia phase of the four types of shifts go as expected. The torque phase takes place before the inertia phase for the power-on upshift and the power-off downshift; see Figures 12(e) and 12(h); the inertia phase takes place before the torque phase for the power-on downshift and the power-off upshift; see Figures 12(f) and 12(g).
6.2. Comparison of Different Methods in OFFTS. In the control of torque phase of clutch-to-clutch shifts, two major problems should be avoided. One is the clutch tie-up and the other is the input speed flare, but they are mutually contradictory and will not happen at the same time. Based on the frame of the shift controller, the torque phase of each shift takes place in the SP2 of the GCF. Thus The ONVCC is in ONTS and the OFFVCC is in OFFTS. The key to avoid clutch tie-up and the input speed flare is to disengage the offgoing clutch at the right time. Therefore, the control of OFFTS is worth exploring.

Figure 13 shows three simulation results of a power-on upshift under the same initial conditions. Three different control methods are used in OFFTS. Only the FF control, an open loop control method, is used in the first one; see Figures 13(a), 13(b), 13(c), and 13(d). During the torque phase, the slip speed of offgoing clutch (see Figure 13(c)) is zero because the torque capacity is higher than the drive torque capacity of offgoing clutch. The clutch tie-up occurs at the end of torque phase (dashed circle in Figure 13(a)); thus the output torque of 6AT vibrates at the beginning of the inertia phase (dashed circle in Figure 13(b)). The FF-PID controller with small gains of $\mathrm{P}$ term and I term is used in the second one; see Figures 13(e), 13(f), 13(g), and 13(h). Because the PID control, a close loop control method, has little effect on the torque capacity of offgoing clutch, the slip speed (see Figure 13(g)) is still zero during the torque phase. But the clutch tie-up and the output torque vibration are reduced; see Figures 13(e) and 13(f). The FF-PID controller with proper gains of $\mathrm{P}$ term and I term is used in the third one; see Figures 13(i), 13(j), 13(k), and 13(l). The small slip speed during the torque phase occurs; see Figure 13(k). This can represent the torque capacity which is approximately equal to the drive torque capacity of offgoing clutch. Thus the offgoing clutch can disengage at the right time when the torque phase is over. Therefore, the clutch tieup and the output torque vibration are avoided; see Figures $13(i)$ and $13(j)$. Note that the slip power caused by the small slip speed of offgoing clutch (see Figure 13(1)) is very small compared to that of oncoming clutch. 
Control current

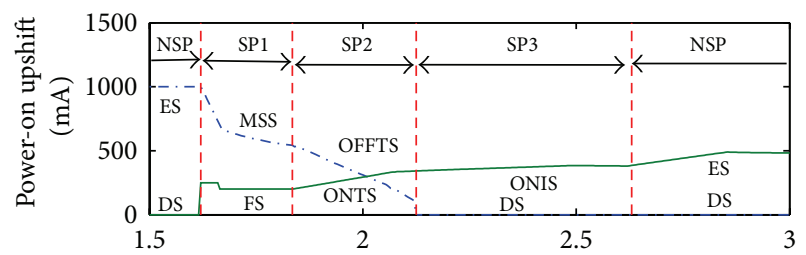

$(t)$

-..- Offgoing

- Oncoming

(a)

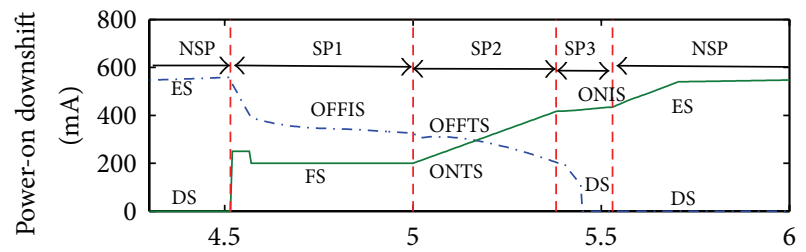

$(t)$

-..- Offgoing

—_ Oncoming

(b)

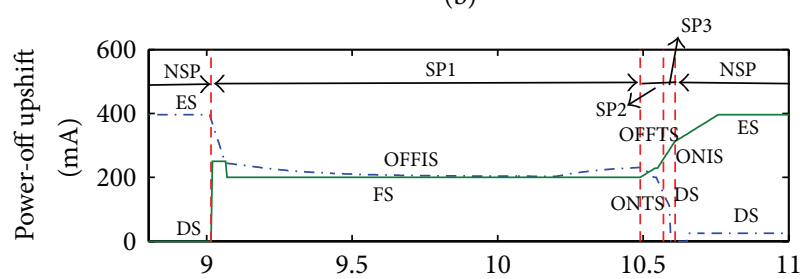

(t)

...- Offgoing

- Oncoming

(c)

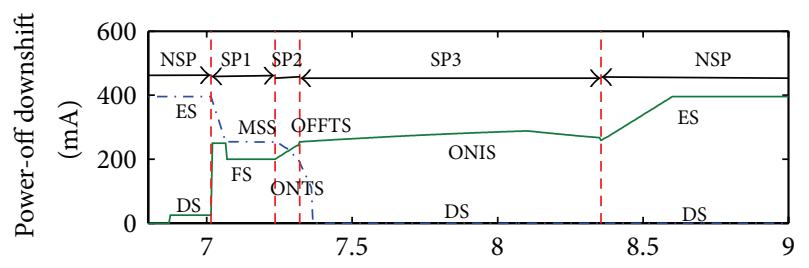

(t)

-..- Offgoing

_ Oncoming

(d)

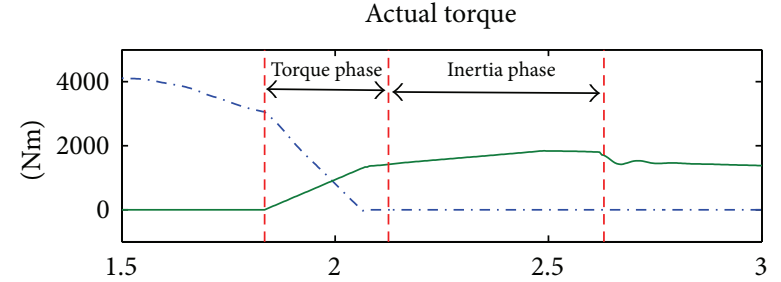

$(t)$

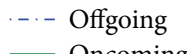

(e)

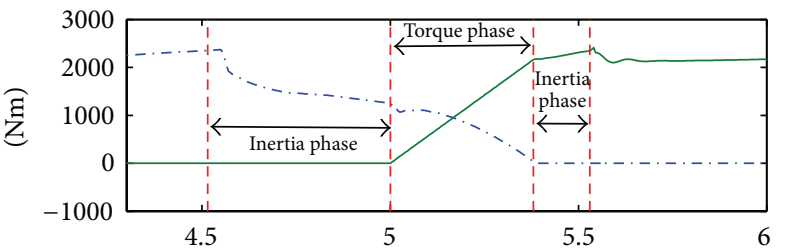

$(t)$

-..- Offgoing

- Oncoming

(f)

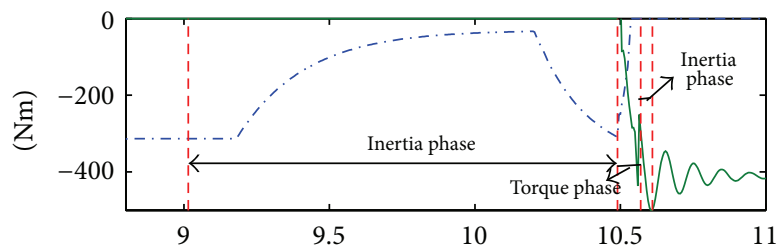

(t)

...- Offgoing

— Oncoming

(g)

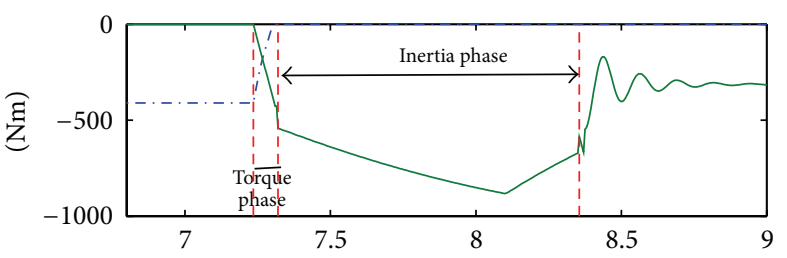

$(t)$

-..- Offgoing

— Oncoming

(h)

FIGURE 12: Simulation results of the four types of shifts.

In order to avoid clutch tie-up under different conditions, a control method, which releases the offgoing clutch quickly by open loop control when the torque capacity is smaller than a low level, is adopted in OFFTS. But the torque capacity should be calibrated properly. Figure 14 shows two simulation results of a power-on upshift with the same initial conditions. In the first one, a small speed flare (see Figure 14(c)) occurs at the end of the torque phase because the OFFTS enters the quick release control stage earlier. And a torque hole occurs in the output torque of the transmission; see Figure 14(b). The quick release control at the right time is shown in the second one; see Figures 14(d), 14(e), and 14(f). The speed flare and the torque hole are avoided.

6.3. Comparison of Different Methods in ONIS. Based on the frame of the shift controller, the inertia phase after torque 


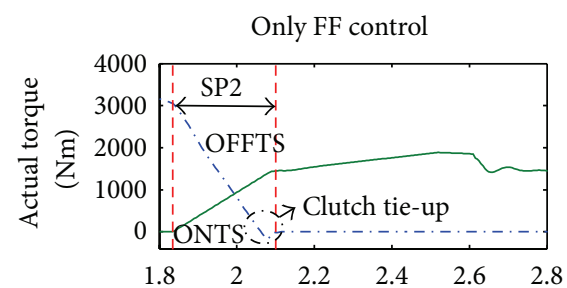

(s)

-..- Offgoing

__ Oncoming

(a)

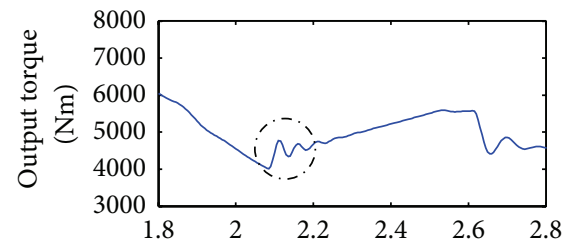

(s)

(b)

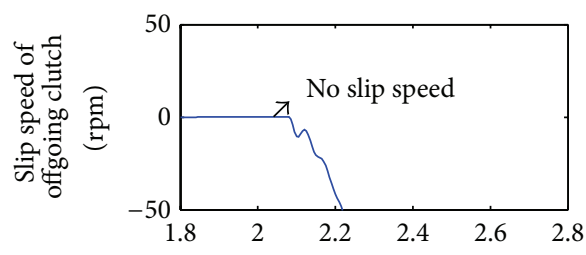

(s)

(c)

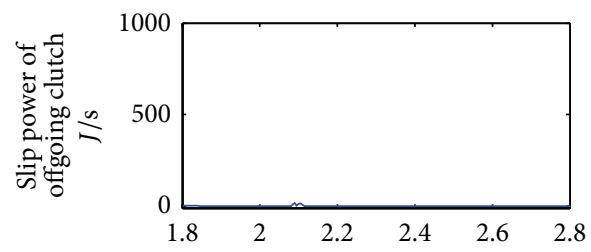

(s)

(d)

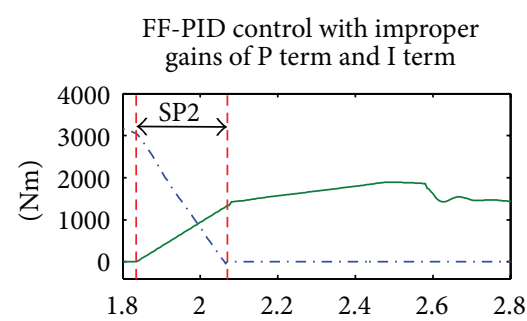

(s)

-..- Offgoing

— Oncoming

(e)

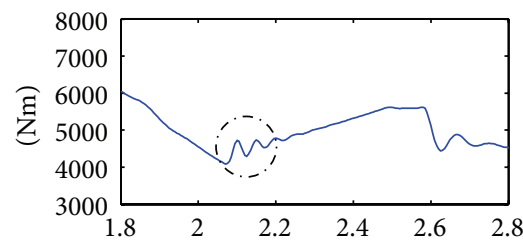

(s)

(f)

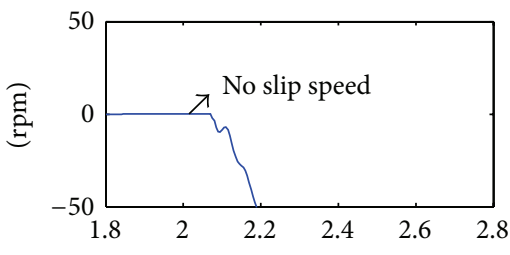

(s)

(g)

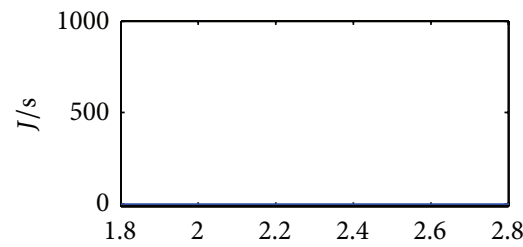

(s)

(h)

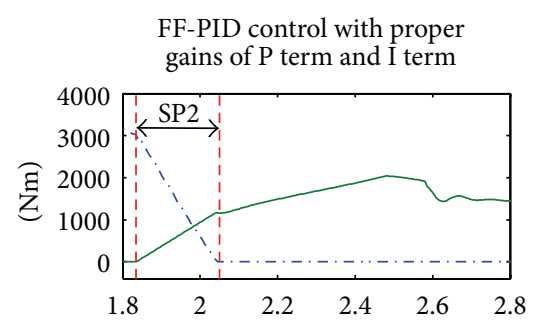

(s)

$$
\text { -..- Offgoing }
$$$$
\text { __ Oncoming }
$$

(i)

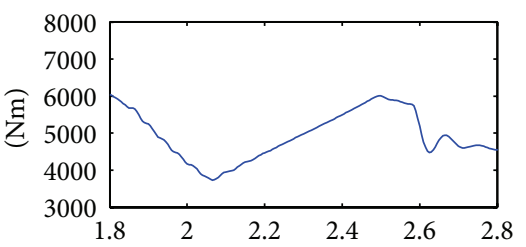

(s)

(j)

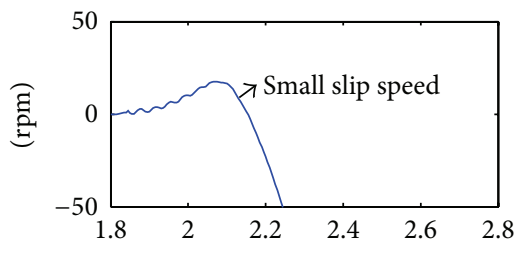

(s)

(k)

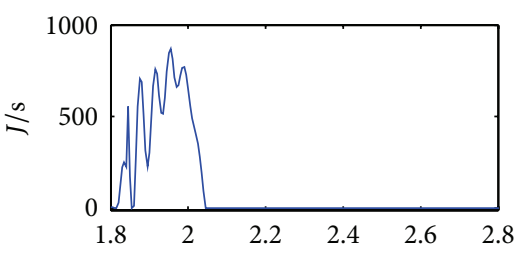

(s)

(1)

FIgURE 13: Method to avoid clutch tie-up.

phase takes place in the SP3 of the GCF. And thus the ONVCC is in ONIS and the OFFVCC is in DS. The object of ONIS is to control the slip speed of oncoming clutch to reach zero gradually.

Figure 15 shows three simulation results of a poweron upshift with the same initial conditions. Three different control methods are used in ONIS. Only the FF-PID control is used in the first one; see Figures 15(a), 15(b), 15(c), and 15(d). There is a torque hump in the actual torque of oncoming clutch (see Figure 15(a)) during the inertia phase because the inertia torque used for the speed change has to be added on the oncoming clutch without the engine torque reduction control. And it causes the torque hump in the output torque of 6AT; see Figure 15(c), which reduces the ride comfort. The FF-PID control with torque limitation is used in the second one; see Figures 15(e), 15(f), 15(g), and 15(h). The torque hump is reduced by mandatory torque limitation in ONIS; see Figure 15(e). Although the torque hump in the output torque (see Figure 15(g)) is reduced, the shift time increases by around $0.3 \mathrm{~s}$ and thus the slip power of oncoming clutch is also increased compared to Figure 15(d). The FF-PID control and the ETR control are all used in the third one; see Figures $15(\mathrm{i}), 15(\mathrm{j}), 15(\mathrm{k})$, and $15(\mathrm{l})$. The engine torque is reduced during the inertia phase; see Figure 15(j). The PID controller plays a supporting role for the synchronization of oncoming clutch. Therefore, the torque hump is reduced significantly and the slip power is also reduced compared to the previous results.

Figure 16 shows three simulation results of a power-on upshift with the same initial conditions. Three ETR methods 


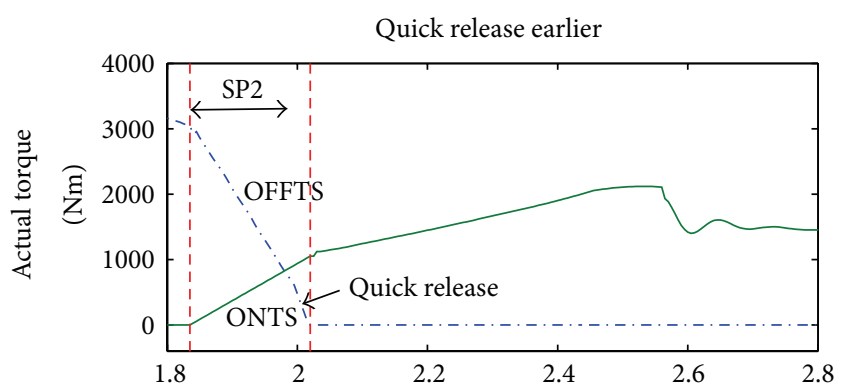

(s)

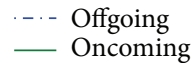

(a)

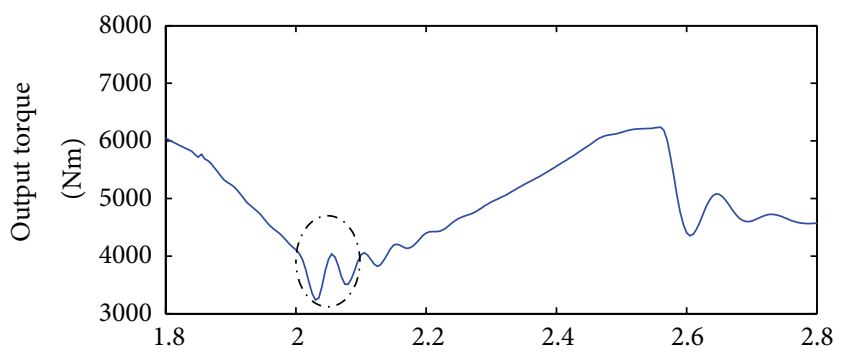

(s)

(b)

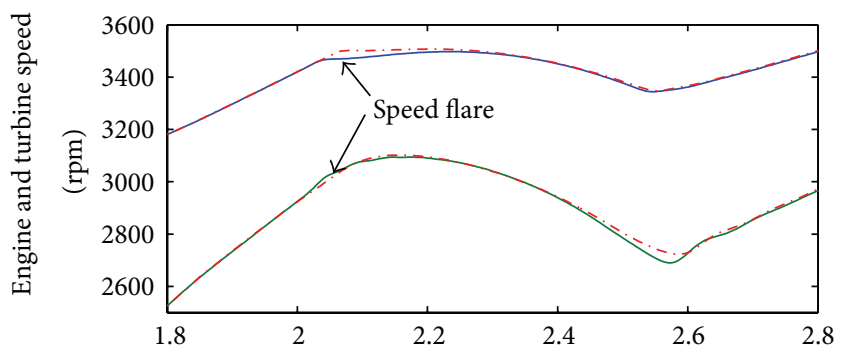

(s)

- Engine speed

— Turbine speed

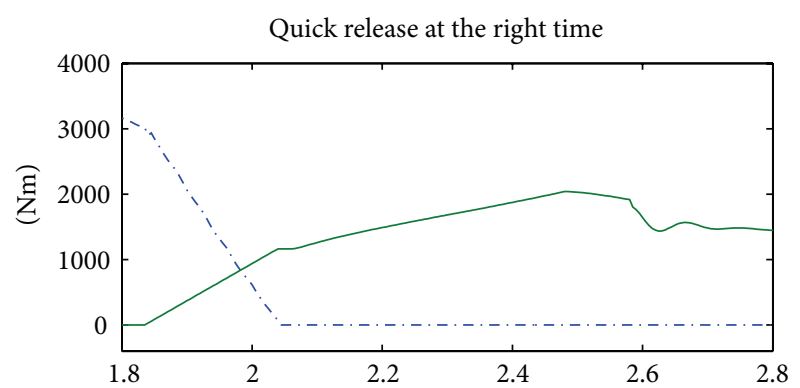

(s)

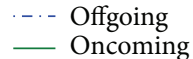

(d)

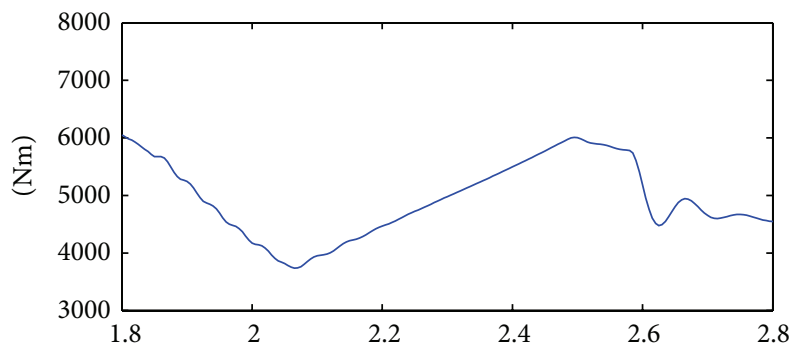

(s)

(e)

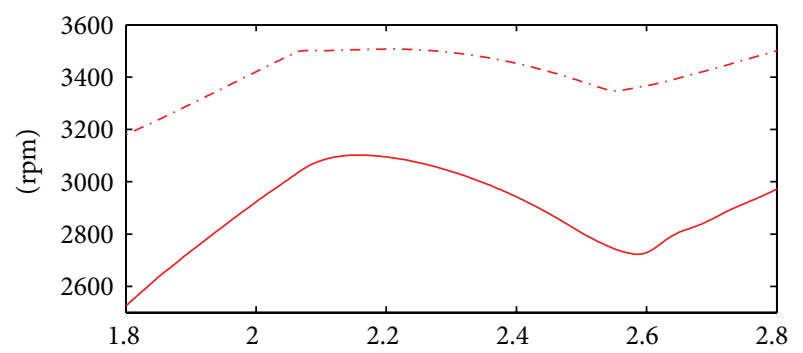

(s)

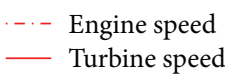

(c)

(f)

FIGURE 14: Method to avoid speed flare.

are used in ONIS. The ETR control with quick recovery of the engine torque at the end of the inertia phase is used in the first one; see Figures 16(a), 16(b), 16(c), and 16(d). There is a big vibration of output torque at the end of inertia phase (see Figure 16(d)) which is caused by the engagement of oncoming clutch. The ETR control with small reduction torque is used in the second one; see Figures 16(e), 16(f), $16(\mathrm{~g})$, and $16(\mathrm{~h})$. The engine reduction torque shown in Figure 16(f) is small comparable to Figure 16(b). And thus the stick vibration (see Figure 16(h)) is reduced, but the shift time is increased. The ETR control with slow recovery is used in the third one; see Figures 16(i), 16(j), 16(k), and 16(l). The slip speed of oncoming clutch decreases to zero gently compared to the previous result. The stick vibration is reduced significantly and the shift time has increased by just $0.05 \mathrm{~s}$.

6.4. Comparison of Different PID Parameters in OFFIS. Based on the frame of the shift controller, the inertia phase before torque phase takes place in the SP1 of the GCF. And thus the ONVCC is in FS and the OFFVCC is in OFFIS. The object of OFFIS is to control the turbine speed to reach the target gear speed level gradually.

Figure 17 shows three simulation results of a power-on downshift with the same initial conditions. Three different PID parameters are used in OFFIS. The FF-PID controller 
FF-PID control without ETR

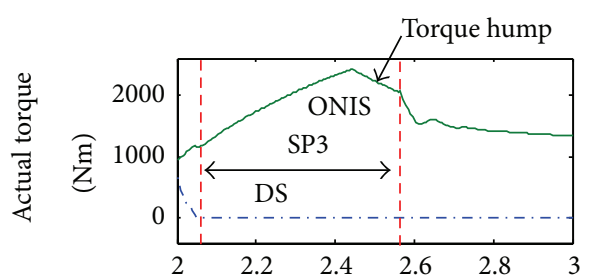

(s)

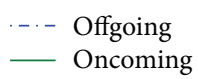

(a)

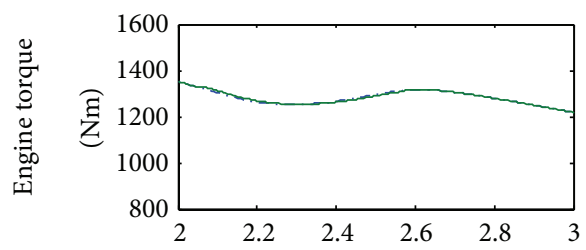

(s)

-.- No intervention

— Intervention

(b)

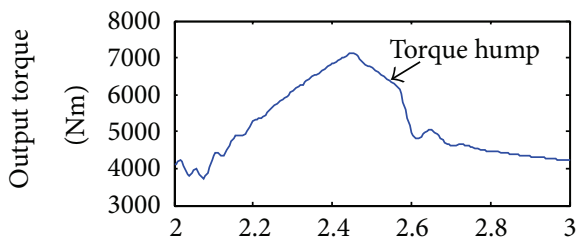

(s)

(c)

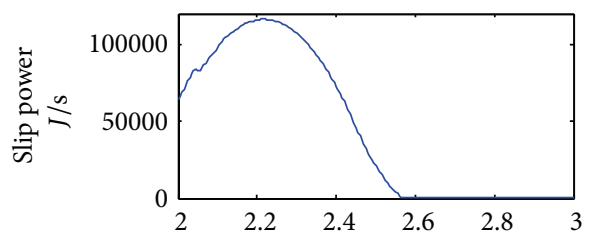

(s)

(d)
FF-PID control with torque limitation

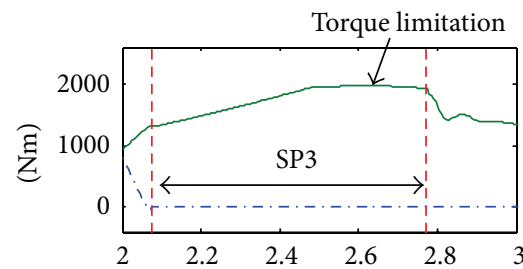

(s)

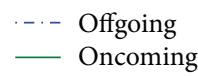

(e)

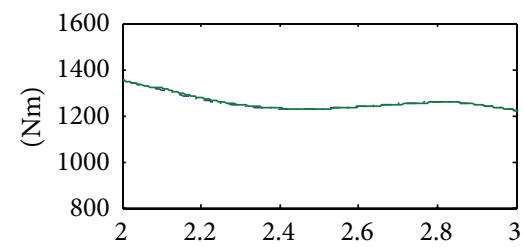

(s)

-.. No intervention

(f)

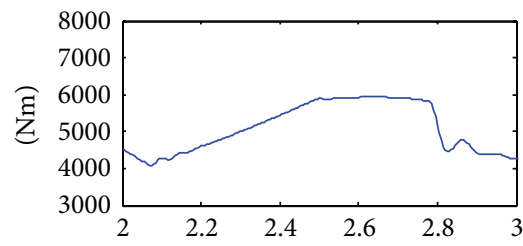

(s)

(g)

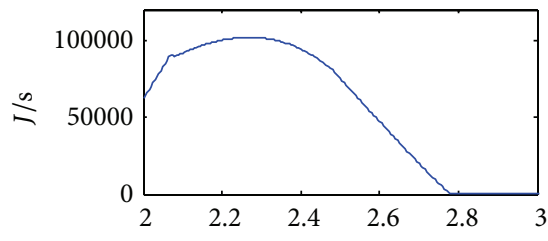

(s)

(h)
FF-PID control with ETR

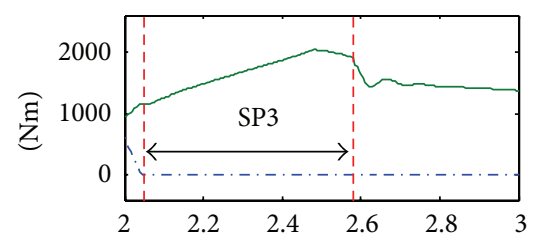

(s)

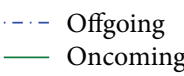

(i)

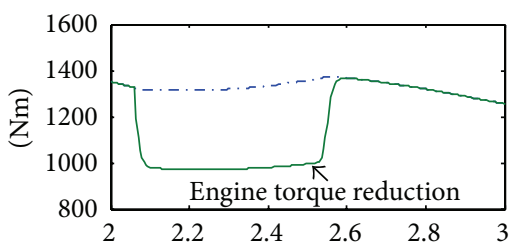

(s)

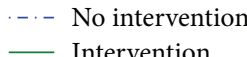

(j)

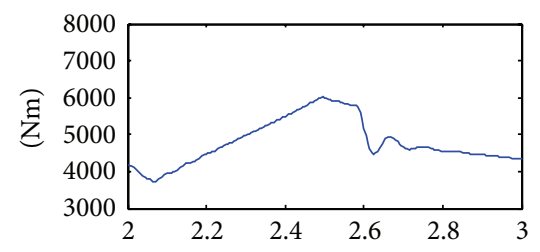

(s)

(k)

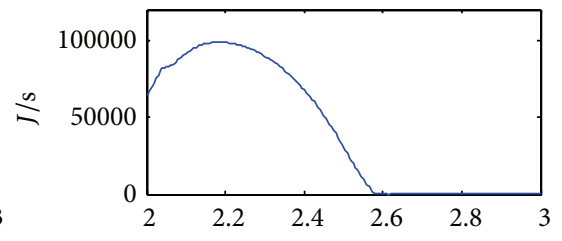

(s)

(l)

FIGURE 15: Inertia phase with and without engine torque reduction control.

with improper $\mathrm{P}$ term and I term is adopted in the first one; see Figures 17(a), 17(b), 17(c), 17(d), and 17(e). The slip speed of oncoming clutch still increases for a while after the inertia phase. Therefore, the duration time of shift is longer and the slip power of oncoming clutch is larger. The FF-PID controller with proper $\mathrm{P}$ term is adopted in the second one; see Figures $17(\mathrm{f}), 17(\mathrm{~g}), 17(\mathrm{~h}), 17(\mathrm{i})$, and $17(\mathrm{j})$. The actual torque of offgoing clutch rises a little at the end of the inertia phase and the turbine speed is "caught" by the offgoing clutch. But there is a small vibration of output torque during the torque phase. The FF-PID controller with proper P term and I term is adopted in the third one; see Figures 17(k), 17(l), 17(m), 17(n), and 17(o).
The turbine speed is "caught" and the slip power of oncoming clutch is reduced without the output torque vibration. The trajectory of the actual torque of offgoing clutch during the torque phase is instructive for the controller.

\section{Conclusions}

In this paper, an equivalent method is proposed to control an AT like a DCT. Two "virtual" clutches, that is, virtual oncoming clutch and virtual offgoing clutch, are imagined at the input side of AT by adopting the torque ratios of the corresponding clutches according to the gear. By this method 


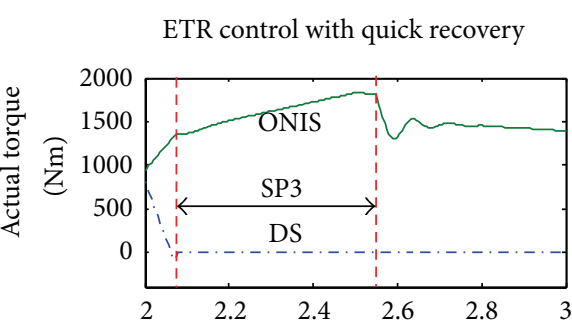

(s)

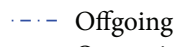

- Oncoming

(a)

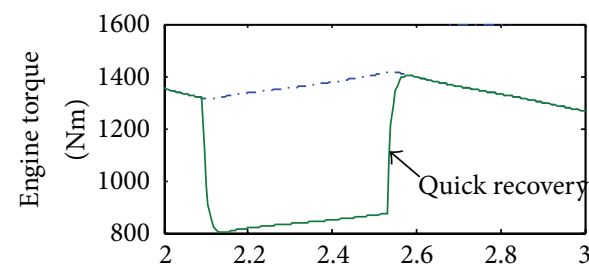

(s)

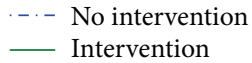

(b)

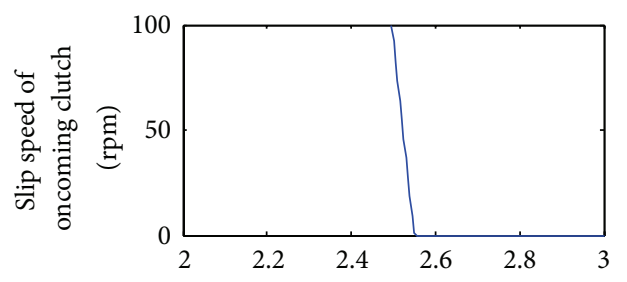

(s)

(c)

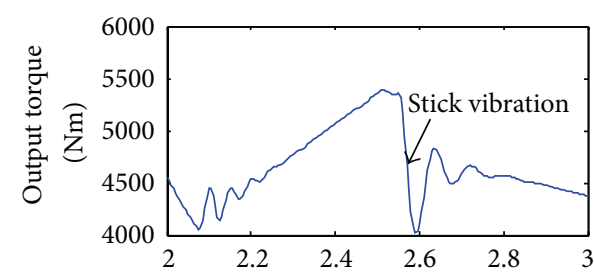

(s)
ETR control with small reduction torque

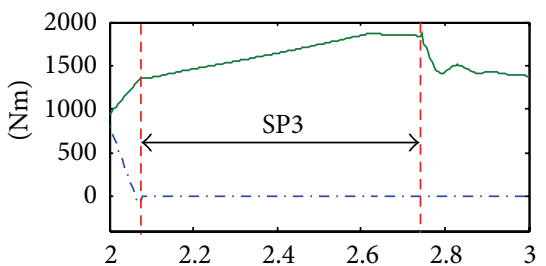

(s)

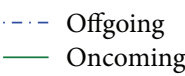

(e)

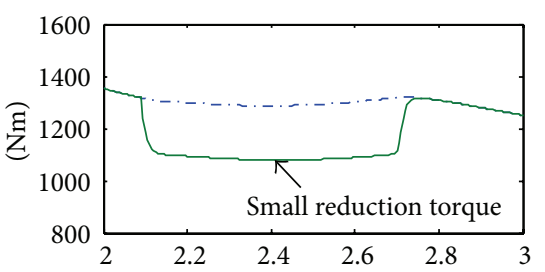

(s)

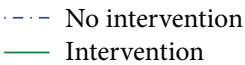

(f)

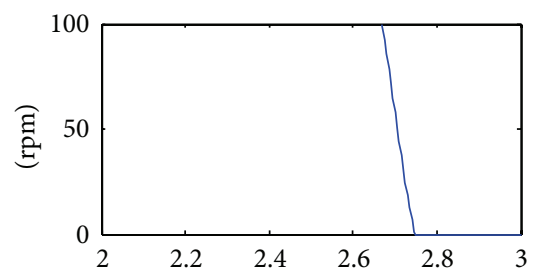

(s)

(g)

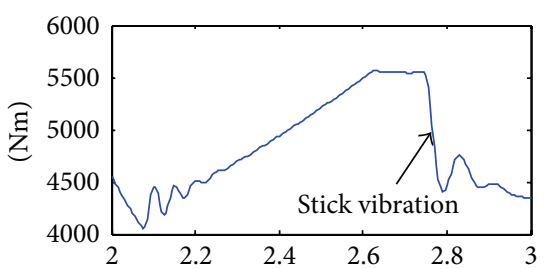

(s)

(h)
ETR control with slow recovery

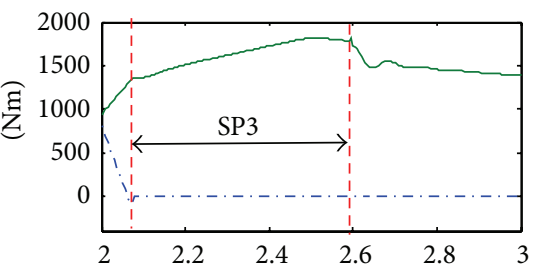

(s)

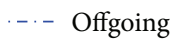

- Oncoming

(i)

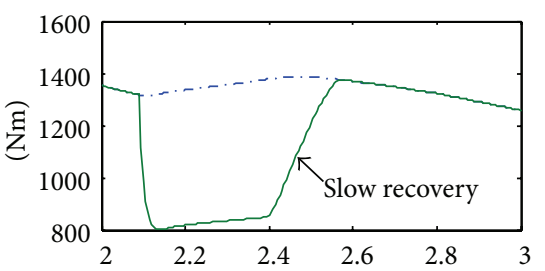

(s)

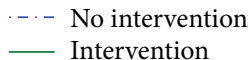

(j)

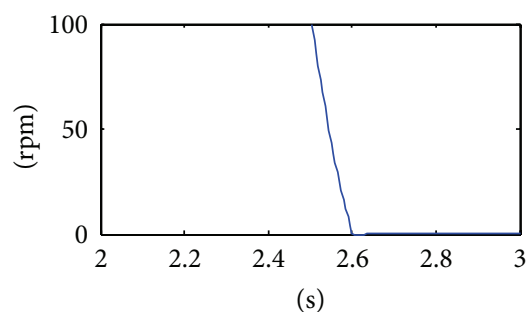

(k)

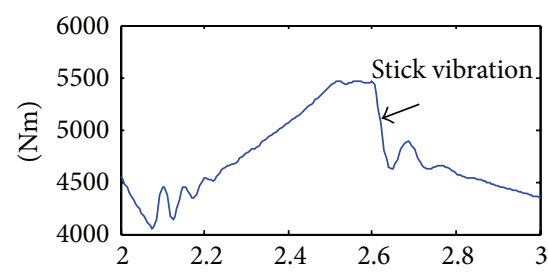

(s)

(1)

FIGURE 16: Engine torque reduction control considering stick vibration.

the six clutches of 6AT can be equivalent to two virtual clutches by the torque ratios of each gear, and thus the same control algorithm can be used to handle the shift processes of different gears to simplify the controller, and thus the demand for the memory of TCU is decreased.

To further simplify the algorithms of the shift controller, the virtual clutch controllers are designed with the same eight states which include all control processes for the four types of clutch-to-clutch shifts. With the powertrain model based on a truck, the virtual clutch controllers are verified by software-in-the-loop simulations. Some typical problems in the clutch-to-clutch shift control are discussed and several control methods are provided to solve these problems. Based on the virtual clutch controllers, the control methods for clutch-to-clutch shifts can be investigated conveniently and a foundation for further research is provided.

\section{Conflict of Interests}

The authors declare that there is no conflict of interests regarding the publication of this paper. 


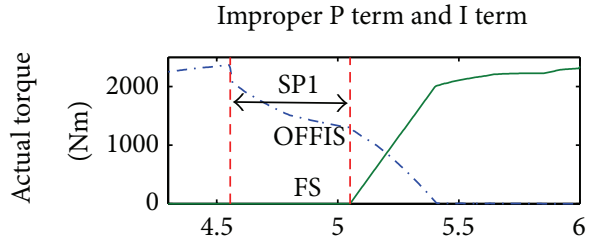

(s)

$$
\begin{array}{ll}
\ldots \text { Offgoing } \\
\text { _ Oncoming }
\end{array}
$$

(a)

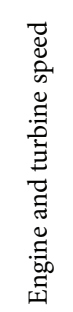

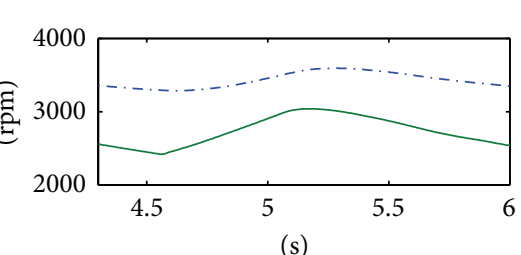

-. - Engine speed

— Turbine speed

(b)

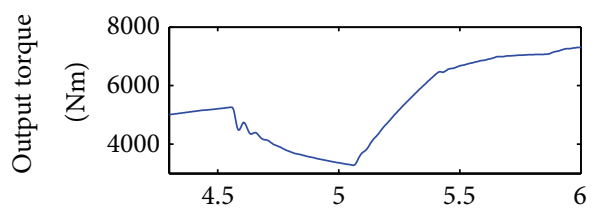

(s)

(c)

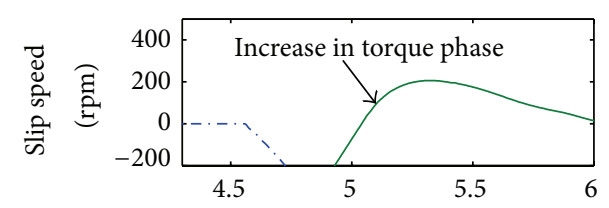

(s)

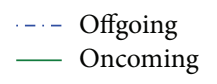

(d)

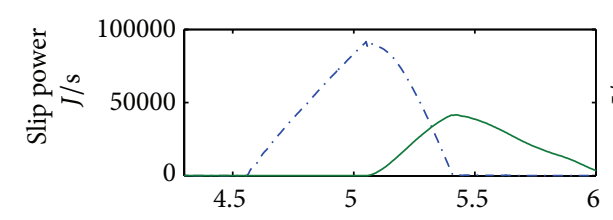

(s)

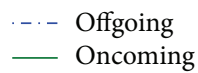

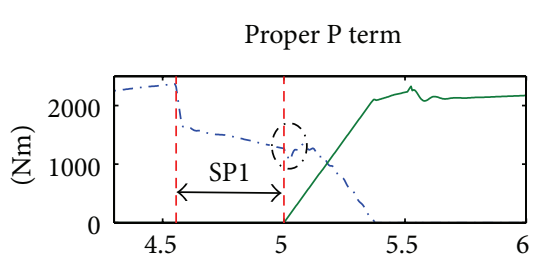

(s)

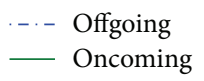

(f)

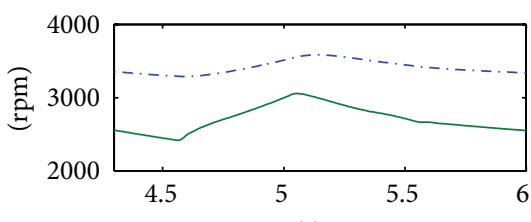

(s)

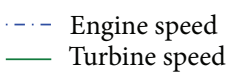

(g)

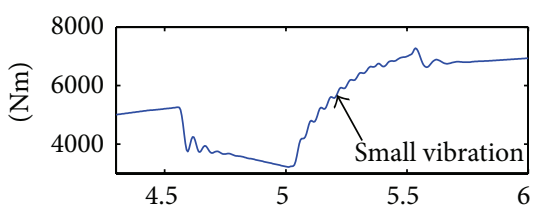

(s)

(h)

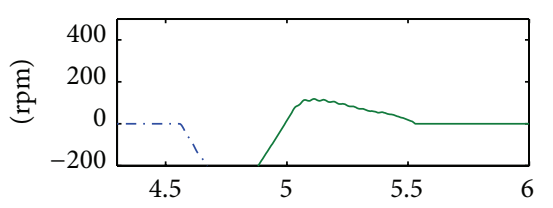

(s)

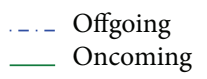

(i)

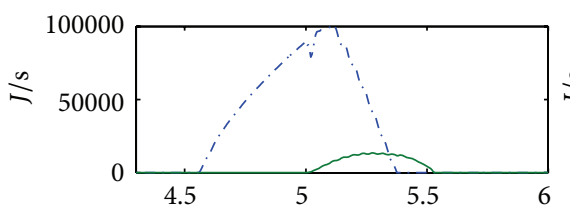

(s)

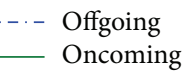

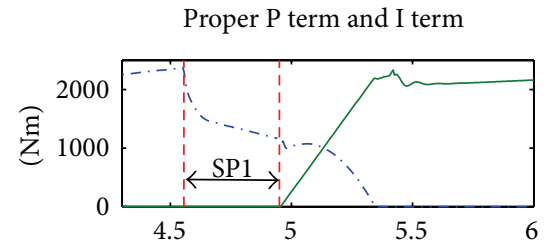

(s)

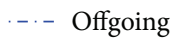

— Oncoming

(k)

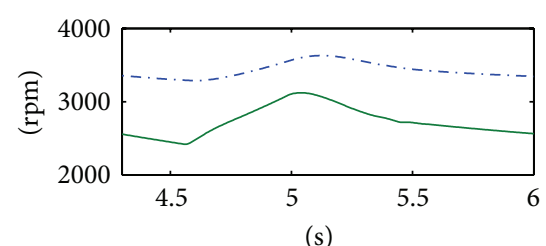

(s)

-.. Engine speed _ Turbine speed

(1)

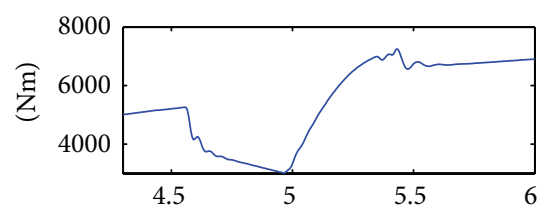

(s)

(m)

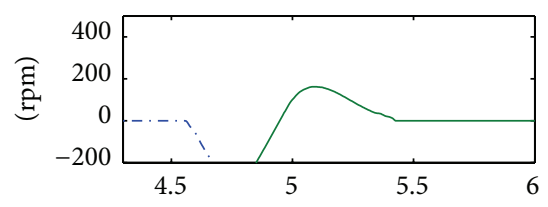

(s)

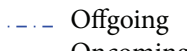

Oncoming

(n)

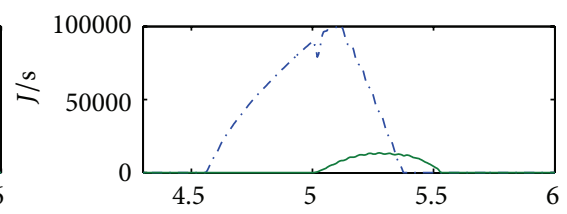

(s)

...- Offgoing

— Oncoming

(o)

FIgURE 17: Results of different PID parameters in OFFIS. 


\section{Acknowledgments}

This study is supported by the National Key Technology R\&D Program (no. 2011BAG11B00) and the National Natural Science Foundation of China (no. 51105017).

\section{References}

[1] J. K. Runde, Modelling and Control of an Automatic Transmission, Massachusetts Institute of Technology, 1986.

[2] A. Haj-Fraj and F. Pfeiffer, "A model based approach for the optimization of gearshifting in automatic transmissions," International Journal of Vehicle Design, vol. 28, no. 1-3, pp. 171188, 2002.

[3] D.-H. Kim, K.-J. Yang, K.-S. Hong, J.-O. Hahn, and K.-I. Lee, "Smooth shift control of automatic transmissions using a robust adaptive scheme with intelligent supervision," International Journal of Vehicle Design, vol. 32, no. 3-4, pp. 250-272, 2003.

[4] S. Bai and R. L. Moses, "Development of a new clutch-to-clutch shift control technology," in Proceedings of the Transmission and Driveline Systems Symposium, SAE paper no. 2002-01-1252, Detroit, Mich, USA, March 2002.

[5] A. Crowther, N. Zhang, D. K. Liu, and J. K. Jeyakumaran, "Analysis and simulation of clutch engagement judder and stickslip in automotive power train systems," Proceedings of the Institution of Mechanical Engineers, Part D, vol. 218, no. 12, pp. 1427-1446, 2004.

[6] M. Goetz, M. C. Levesley, and D. A. Crolla, "Integrated powertrain control of gearshifts on twin clutch transmissions," in Proceeding of Transmission \& Driveline Symposium, SAE paper 2004-01-1637, Detroit, Mich, USA, 2004.

[7] M. Goetz, M. C. Levesley, and D. A. Crolla, "Dynamics and control of gearshifts on twin-clutch transmissions," Proceedings of the Institution of Mechanical Engineers, Part D: Journal of Automobile Engineering, vol. 219, no. 8, pp. 951-963, 2005.

[8] Y. Liu, D. Qin, H. Jiang, and Y. Zhang, "A systematic model for dynamics and control of dual clutch transmissions," Journal of Mechanical Design, vol. 131, no. 6, Article ID 061012, 2009.

[9] Y. Liu, D. Qin, H. Jiang, and Y. Zhang, "Shift control strategy and experimental validation for dry dual clutch transmissions," Mechanism and Machine Theory, vol. 75, pp. 41-53, 2014.

[10] P. D. Walker, N. Zhang, and R. Tamba, "Control of gear shifts in dual clutch transmission powertrains," Mechanical Systems and Signal Processing, vol. 25, no. 6, pp. 1923-1936, 2011.

[11] P. D. Walker and N. Zhang, "Modelling of dual clutch transmission equipped powertrains for shift transient simulations," Mechanism and Machine Theory, vol. 60, pp. 47-59, 2013.

[12] S. Bai, J. Maguire, and H. Peng, Dynamic Analysis and Control System Design of Automatic Transmissions, Society of Automotive Engineers, Warrendale, Pa, USA, 2013.

[13] C. F. Xie, Q. Wang, and Y. Cheng, Dynamics, Higher Education Press, Beijing, China, 2004.

[14] A. Wohnhaas, D. Hötzer, and U. Sailer, Modulares Simulationsmodell eines Kfz-Antriebsstrangs unter Berücksichtigung von Nichtlinearitäten und Kupplungsvorgängen, VDI-Verlag, Düsseldorf, Germany, 1995. 


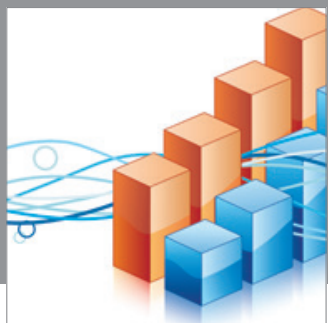

Advances in

Operations Research

mansans

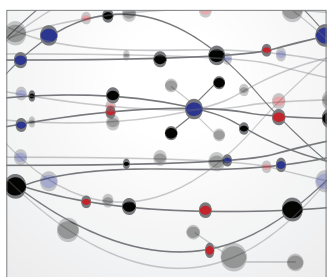

The Scientific World Journal
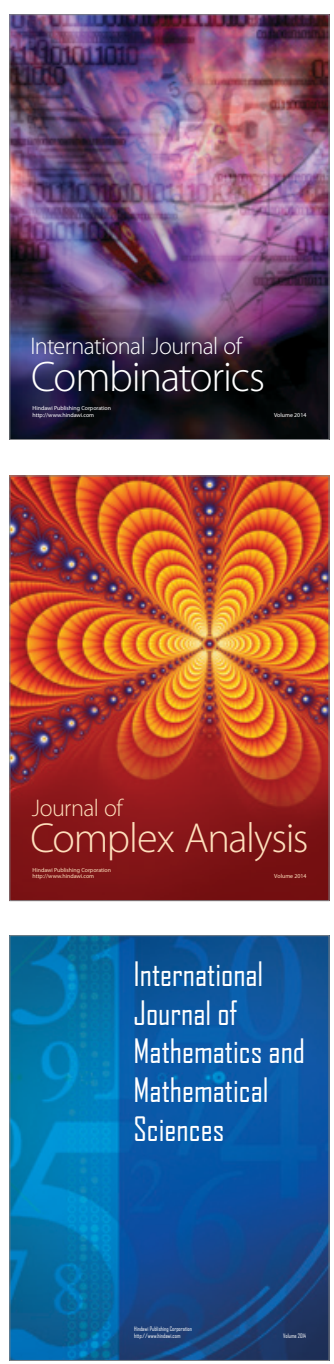
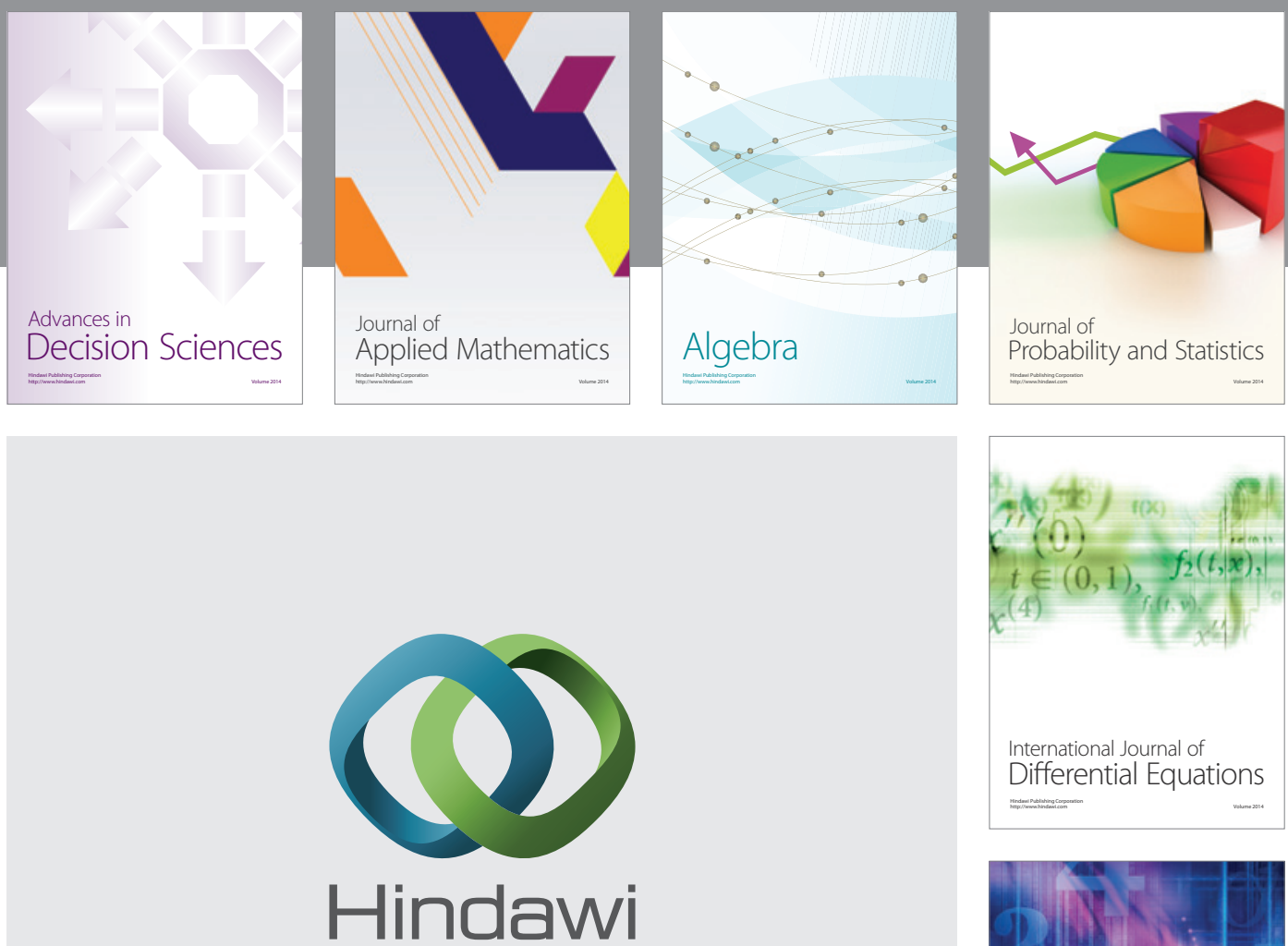

Submit your manuscripts at http://www.hindawi.com
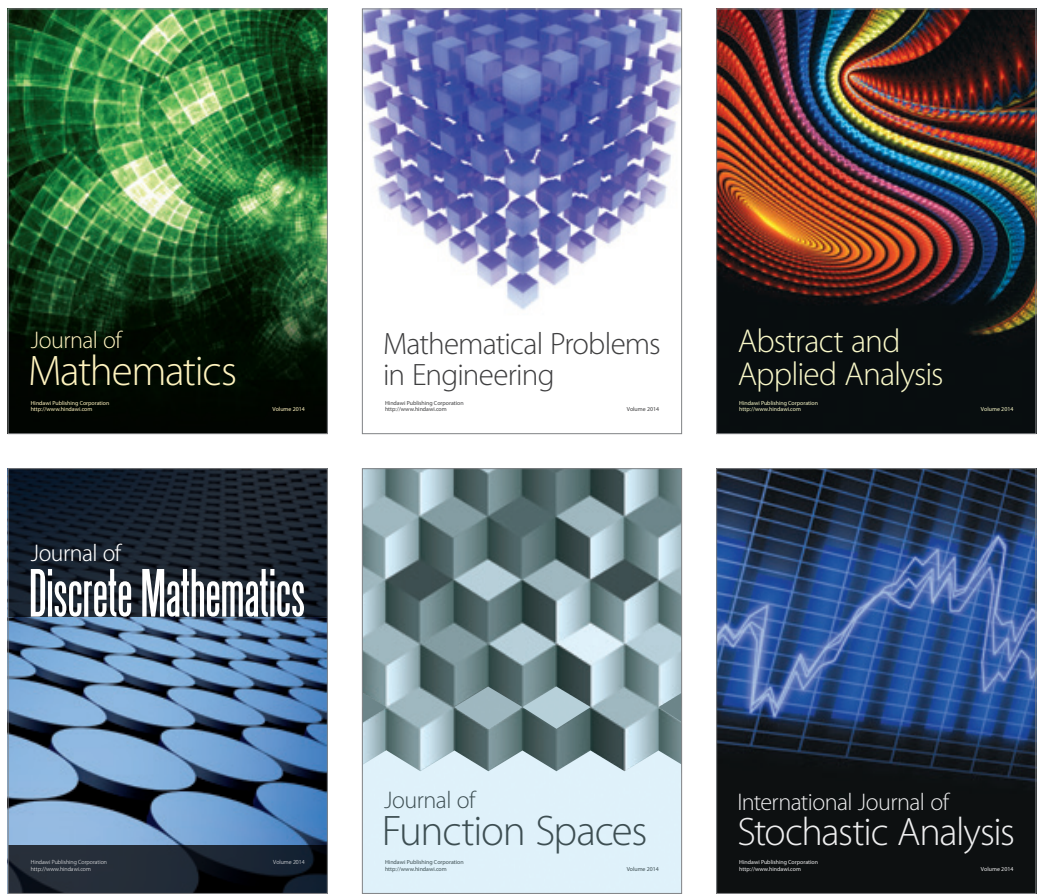

Journal of

Function Spaces

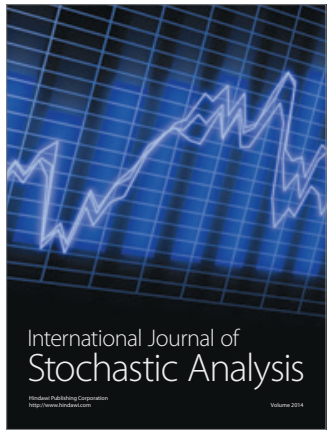

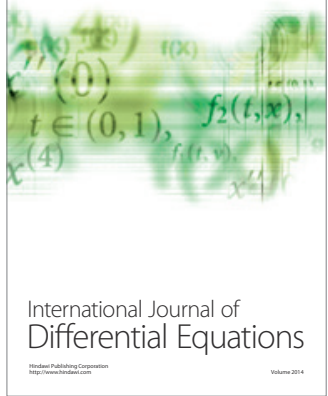
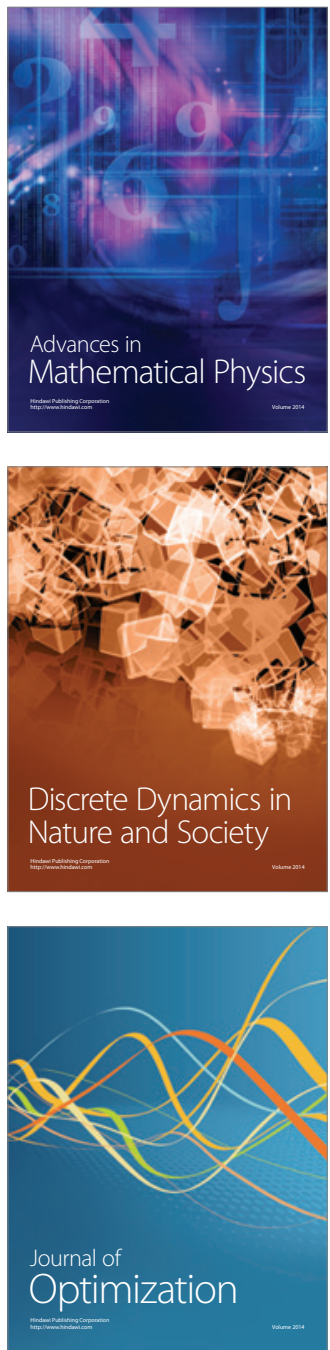